Document downloaded from:

http://hdl.handle.net/10251/52115

This paper must be cited as:

Serrano Cruz, JR.; Climent Puchades, H.; Piqueras Cabrera, P.; Angiolini, E. (2014). Analysis of fluid-dynamic guidelines in diesel particulate filter sizing for fuel consumption reduction in post-turbo and pre-turbo placement. Applied Energy. 132:507-523. doi:10.1016/j.apenergy.2014.07.043.

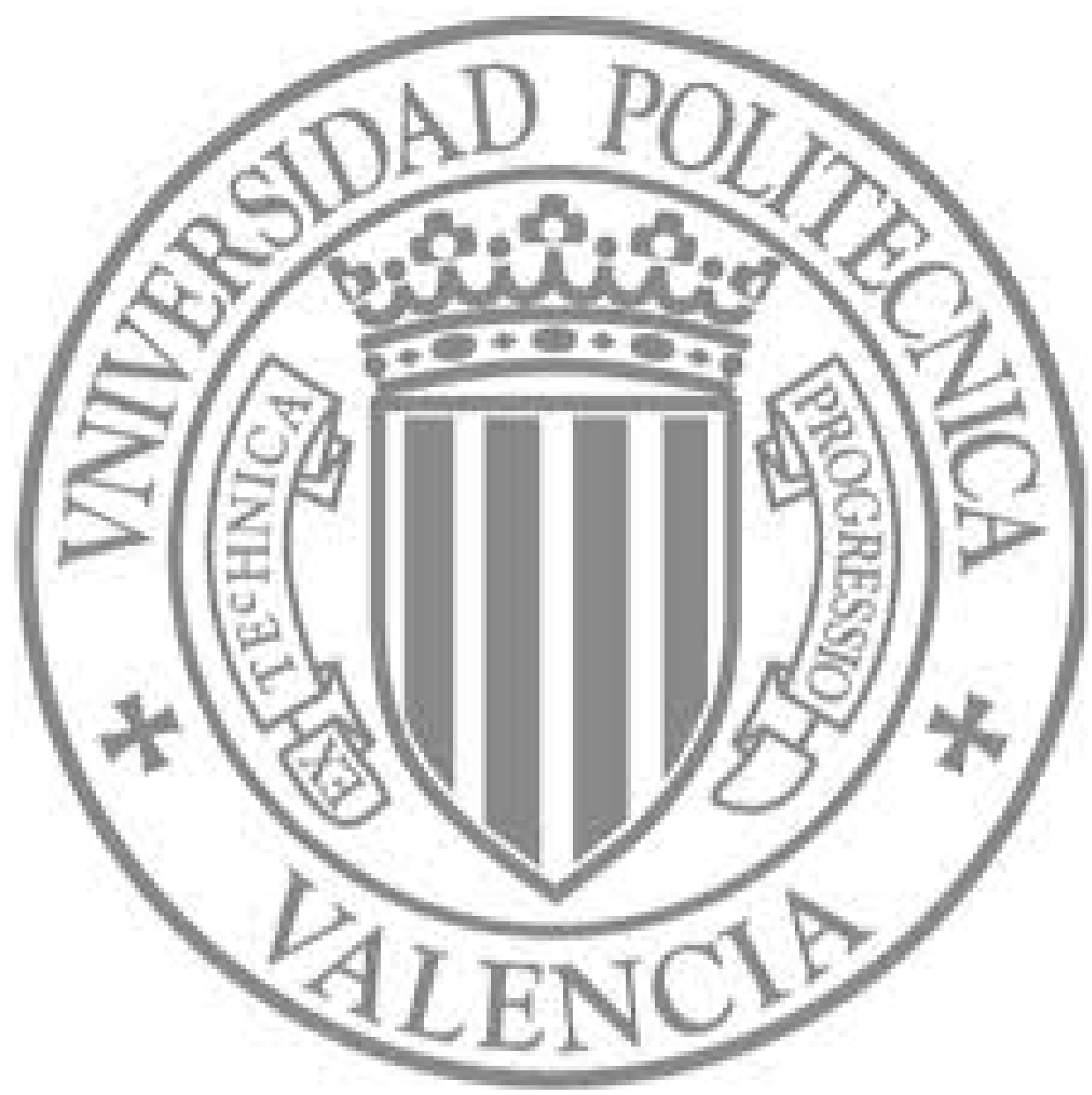

The final publication is available at

http://dx.doi.org/10.1016/j.apenergy.2014.07.043

Copyright Elsevier 


\title{
Analysis of fluid-dynamic guidelines in diesel particulate filter sizing for fuel consumption reduction in post-turbo and pre-turbo placement
}

\author{
J.R. Serrano, H. Climent, P. Piqueras*, E. Angiolini \\ Universitat Politècnica de València, CMT-Motores Térmicos, Camino de Vera s/n, 46022 Valencia, Spain.
}

\begin{abstract}
Wall-flow particulate filters are in the present days a standard aftertreatment system widely used in diesel engines to reduce particle emissions and meet emission regulations. This paper deals with the analysis of the macro- and meso-geometry definition of the DPF monoliths from a fluid-dynamic modelling approach. Focus is driven to the analysis of the influence on pressure drop and hence on engine fuel economy.

The influence of the DPF volume on the engine performance is analysed with a gas dynamic software including both post-turbo and pre-turbo placement under clean and soot loading conditions. A swept in cell density is also considered for different thermal integrity factors. This approach allows analysing the trends in pressure drop and cell unit geometric parameters defining the monolith thermal and mechanical performance. A discussion considering constant specific filtration area and constant filtration area is performed providing a comprehensive understanding of the DPF and engine response as volume and cellular geometry are changed. Results are leading to rigorously justify known but usually empirical guidelines for DPF design in post-turbo applications. A discussion on the potential for monolith volume reduction in pre-turbo applications with respect to the post-turbo baseline is addressed. This is based on the very low sensitivity of fuel consumption and pressure drop both to volume reduction and soot and ash loading with pre-turbo DPF configuration.
\end{abstract}

Keywords: Diesel engine, DPF sizing, pressure-drop, fuel consumption, pre-turbo aftertreatment

\section{Introduction}

Diesel engines have gained in recent years in growth acceptance with respect to other internal combustion engine alternatives and have found its way in numerous applications [1]. The reason explaining the increasing market penetration of diesel engines in ground transport applications, both for passenger and heavy duty use, is found in its improved performance and higher efficiency leading to lower $\mathrm{CO}_{2}$ emissions [2]. Increasingly restrictive emission standards have also played an important role in the development of more environmentally friendly engines.

${ }^{*}$ P. Piqueras. CMT-Motores Térmicos, Universitat Politècnica de València, Camino de Vera s/n, 46022 Valencia, Spain. Phone: +34963877650 Fax: +34 963877659 e-mail: pedpicab@mot.upv.es 
Besides the improvement of different engine aspects such as turbocharging [3], novel combustion concepts [4], use of fuel blends [5] or new EGR route solutions [6], the compliance of current and incoming emission standards is requiring the use of aftertreatment systems [7]. Between these systems, diesel particulate filter (DPF), and in particular wall-flow type DPF, is the most effective solution for controlling particulate matter emissions in diesel engines.

Wall-flow DPFs are honeycomb monolithic structures with alternatively plugged channels at each end. The gas flow entering the inlet channels is forced to pass through the porous substrate walls, where the soot particulates are deposited and accumulated until the regeneration takes place. These systems have been traditionally placed downstream of the turbine at the tail end of the exhaust line. However, higher temperature upstream of the turbine and the lower fuel penalty are boosting interest for the pre-turbo DPF configuration in heavy-duty [8] and passenger car engines [9]. The required condition is the use of two-stage turbocharging systems or combined mechanical and turbo charging systems. These boosting architectures are required to avoid the detrimental effect of ceramics thermal inertia on the engine dynamic response [10].

One of the additional latent advantages of pre-turbo DPF placement is the potential for volume reduction because of the lower pressure drop that a given DPF provides with respect to the traditional post-turbo location [11]. It can become a source of cost savings due to the fact that more than 50\% of control emission technologies are coming from aftertreatment systems in standard passenger car engines [12]. Aftertreatment cost is distributed in DOC (10\%), DPF (40\%) and SCR (50\%) [12]. Other studies, such as the reports from EPA/NHTS [13] and NAS [14], provide even higher cost of the aftertreatment systems. From these data, and assuming that the whole aftertreatment system to fulfil Euro 6 is estimated to reach circa $30 \%$ of the engine cost, the DPF is representing around $12 \%$ of it.

DPF volume in post-turbo placement is usually ranging between 1.5 and 2.5 times the engine displacement [12]. The final volume is selected as compromise between packaging restrictions and capability for soot and ash accumulation. Besides the volume, the cellular geometry is also key to define the DPF performance. Several studies have been conducted to analyse the most efficient cellular geometry to minimise the DPF pressure drop in clean [15] and soot loaded monoliths [16]. However, these studies are based on honeycomb cell-size optimisation keeping constant porous wall thickness. Despite the monolith channel pressure drop cell size and geometry optimisation [17], the performance of the DPF concerning thermal response [18] or mechanical resistance must be also considered. These characteristics are usually assessed by means of a series of cell unit geometric parameters [19] that can be defined for several cell cross-section geometries [20]. These parameters are widely applied to the pre-design of through-flow monolith for catalytic applications [21]. In this paper the main cell unit geometric parameters are adapted to the specific wall-flow monolithic structure with square channels. The objective is to analyse with a gas dynamics code the influence of the DPF volume and the cellular geometry on the pressure drop and engine fuel consumption accounting for the DPF placement with respect to the turbine. The cellular geometry is modified sweeping a cell density range as a function of the monolith volume keeping constant the thermal integrity factor (TIF), which is additionally parameterized. This 
strategy gives as a result a wide set of data allowing a comprehensive discussion to define and justify guidelines for DPF pre-design in post-turbo and pre-turbo placement.

\section{Methodology}

The results shown in this work have been obtained from a modelling approach based on the use of the open-source gas dynamic software OpenWAM ${ }^{\mathrm{TM}}[22,23]$ for internal combustion engines and components computation. Focus is driven to analyse the influence on the engine performance of the DPF pressure drop change as a function of the DPF macro-and meso-geometry. The DPF model assumes one-dimensional unsteady compressible and non-homentropic flow [24] to manage the pulsating flow characteristics taking place in pre-turbo placement. The fluid-dynamic modelling is completed accounting for heat transfer phenomena [25] and porous media properties as a function of the DPF soot loading [26].

The baseline engine is a turbocharged diesel engine for passenger car application. The main characteristics of the engine are shown in Table 1. The engine was tested with post-turbo and pre-turbo aftertreatment configuration in order to provide a reference for the subsequent engine and DPF modelling study. The aftertreatment system in post-turbo placement is composed of a close-coupled DOC next to the VGT, an underfloor DOC and a DPF. The preturbo aftertreatment architecture is simplified by removing the close-coupled DOC and keeping only the underfloor aftertreatment directly placed upstream of the turbine. The architecture for this study was pre-turbo DPF followed by the DOC. The relative DPF and DOC placement in pre-turbo configuration has not relevance on sizing since the change in DPF pressure drop is small [11]. The selection of this kind of pre-turbo aftertreatment architecture is justified by the need to improve the aftertreatment warm-up [27] and as a solution to protect the VGT from ceramic debris coming from an eventual DPF fault by making use of a metallic DOC [28].

Figure 1 shows the comparison between experimental data and modelled results for the variables of interest in this study. The engine was tested at medium high load ranging from $1500 \mathrm{rpm}$ to $3000 \mathrm{rpm}$ in engine speed; the engine load is decreasing with engine speed being $90 \%$ at $1500 \mathrm{rpm}, 80 \%$ at $2000 \mathrm{rpm}$ and $2500 \mathrm{rpm}$, and $70 \%$ at $3000 \mathrm{rpm}$. The model shows good accuracy and sensitivity to predict the engine performance and the DPF pressure drop any of the aftertreatment placement and operating point.

The modelling work performed from the engine model setup has been carried out in the operating point at $2500 \mathrm{rpm}$ and $80 \%$ in engine load. For all the simulations, the ambient conditions have been set to 1.025 bar and $27^{\circ} \mathrm{C}$ both for pre-turbo and post-turbo aftertreatment configurations. The injected fuel mass flow and the equivalence ratio are also kept constant in the study and equal to the experimental values obtained with pre-turbo aftertreatment configuration. The VGT position is changed as the DPF geometry is modified (different DPF pressure drop) in order to kept constant the air mass flow and hence the equivalence ratio. 


\subsection{DPF geometry study definition}

The proposed parametric study affecting the geometry of the DPF covers the change in volume and cell density.

The DPF installed in the engine during the testing phase is taken as reference. The main characteristics of this DPF are summarised in Table 2.

A series of cell unit geometric parameters, whose value can be considered as state of the art, is given in Table 2 to be used as baseline for following discussions. The filtration area of the DPF is defined as a function of the specific filtration area (SFA) and the effective monolith volume, which in turn is a function of the monolith diameter $(D)$ and the channel length $\left(L_{e}\right)$ :

$$
A_{f}=S F A \frac{\pi D^{2}}{4} L_{e}
$$

Being the channel length

$$
L_{e}=L-L_{p l u g}
$$

and taking into account the square geometry of the cells, the specific filtration area is defined as:

$$
S F A=\frac{2 \alpha}{\left(\alpha+w_{w}\right)^{2}}
$$

The filtration area provides information about the capability for soot and ash accumulation and the resulting pressure drop. The higher the filtration area the lower the porous medium contribution to the pressure drop because of the influence on filtration velocity and particulate layer thickness. It also influences the regeneration rate since is directly affecting the catalyst surface and loading, the gas to solid contact surface and the dwell time across the wall. The SFA, which is half the SGA, is related to the filtration area accounting for the required volume to get it. Therefore, the higher the SFA for a given volume the better regeneration dynamics and the lower the pressure drop in soot loaded DPFs. However, the change in SFA is not dependent on macro-geometry, as filtration area is, but on meso-monolith or cellular geometry through the honeycomb cell size $(\alpha)$ and the porous wall thickness $\left(w_{w}\right)$. Therefore, other cell unit parameters are related to the specific filtration area. It is the case of the cell density $(\sigma)$, which is defined as:

$$
\sigma=\frac{1}{\left(\alpha+w_{w}\right)^{2}}=\frac{S F A}{2 \alpha}
$$

The open frontal area (OFA) is also accounting for the effect of the pressure drop, in this case inertial contributions due to local flow contraction and expansion at inlet and outlet DPF monolith respectively [24]. For a wall-flow monolith, OFA is defined according to:

$$
O F A=\frac{\alpha^{2}}{2\left(\alpha+w_{w}\right)^{2}}=\frac{\alpha S F A}{4}
$$


Other parameters of interest are those related to the thermal and mechanical response of the monolith. Concerning thermal behaviour, the light-off factor (LOF) is considered in Table 2 for a wall-flow honeycomb structure:

$$
L O F=\frac{1}{4}\left(\frac{S F A}{O F A}-2 S F A\right)
$$

The LOF is accounting for the light-off performance of the monolith [19]. In DPF application, it is representative of the substrate thermal response under transient operation. During steady-state conditions, the heat transfer is related to the bulk heat transfer parameter (HTP). Taking into account SFA and OFA definitions in wall-flow monoliths HTP is given by:

$$
H T P=\frac{1}{2} N u \frac{S F A^{2}}{O F A}
$$

These parameters indicate that the higher the SFA the faster wall temperature increase under transient operation but the higher the gas heat losses for the same OFA.

Finally, Table 2 includes mechanical parameters such as the thermal integrity factor (TIF), the mechanical integrity factor (MIF) and the strain tolerance parameter (STP):

$$
\begin{gathered}
T I F=\frac{\alpha+w_{w}}{w_{w}} \\
M I F=\frac{w_{w}^{2}}{\left(\alpha+w_{w}\right) \alpha} \\
S T P=T I F(1-2 O F A)
\end{gathered}
$$

The TIF is proportional to the maximum temperature gradient that the monolith can withstand when is subjected to thermal cycles [19]. MIF and STP are parameters representing the geometric contribution to the mechanical resistance of the substrate. The MIF is defining the load carrying limit of a cell unit, which is given by the diagonal of the cell [19]. From its value it is possible to obtain the load carrying capability accounting for the tensile strength of the wall $\left(\sigma_{w}\right)$, which is constant if the porosity wall is not modified [21], as assumed in this study:

$$
F=\frac{2}{3} \sigma_{w} M I F
$$

The STP is an indicator of the thermal durability that considers the cellular geometry influence on the strain tolerance (ST) [29], which is defined as:

$$
\begin{aligned}
S T & =\frac{M O R_{z}}{E_{z}}= \\
& =\frac{\frac{3}{5} \sigma_{w}(1-2 O F A)}{\frac{2 E_{o}}{T I F}\left(\frac{1-\varepsilon}{1+4 \varepsilon}\right)} \sim T I F(1-2 O F A)=S T P
\end{aligned}
$$


According to the definition of these parameters, the parametric study comprises the DPF placement in pre-turbo and post-turbo location and the change in monolith volume, cell density, TIF and soot mass loading. Variations in monolith geometry and soot loading are performed according to the following considerations:

- The monolith volume has been reduced by $60 \%$ of its nominal value accounting for a discretization into 5 volumes. The reduction has been performed by modifying the monolith diameter in steps of $10 \%$ from its nominal value, with the only exception of the minimum diameter. This has a reduction of $33.5 \%$ from the nominal value to provide the $40 \%$ of volume reduction. Moreover, steps in diameter provide more resolution in the region of low volume because of computed points are closer. The monolith length has been kept constant. It is due to the fact that the DPF pressure drop is sensitive to volume through diameter change being the length effect almost negligible [30].

- The cell density has been swept from 100 to $500 \mathrm{cpsi}$ with steps of $50 \mathrm{cpsi}$. It leads to compute 9 cell densities that combined with the volume discretization provide 45 geometries to be modelled. Higher values of cell density have been avoided because of soot plugging issues [31]. As pointed out by eq. 4 , the change in cell density has two degrees of freedom, i.e. $\alpha$ and $w_{w}$. To prevent from an arbitrary change in the cellular geometry, the cell density variation has been performed imposing constant TIF, which involves that the $\alpha$ to $w_{w}$ ratio must be kept constant when changing the cell density:

$$
T I F=\frac{\alpha+w_{w}}{w_{w}} \rightarrow \frac{\alpha}{w_{w}}=T I F-1
$$

The study comprises three TIF values in order to account for the effect of the TIF change on the engine response.

- Every DPF geometry (volume, cell density and TIF definition) has been computed for clean DPF (soot and ash free substrate) and $5 \mathrm{~g}$ of soot mass loading. Such a soot mass loading seems to be a low value but its choice is based on test results. After the steady-state tests of operating points shown in Figure 1, the maximum soot mass loading in the post-turbo location was $5 \mathrm{~g}$ (less than $0.5 \mathrm{~g}$ in pre-turbo location). Additionally, as previously indicated, the study is performed at constant injected fuel mass and equivalence ratio, obtaining the last by controlling the VGT position. In post-turbo placement, a high DPF soot mass loading in small DPF volumes can avoid to get the desired equivalence ratio in the medium-high engine load range even fully closing the VGT operating. It is because of the increasing engine back-pressure as it will be shown forward in Section 3 . Therefore, any other scenario for DPF soot mass loading has not been considered in order not to affect the boundaries of this study. 


\section{Results of the parametric study}

\subsection{Clean DPF conditions}

According to the described parametric study in Section 2.1, Figure 2 represents the DPF pressure drop variation as a function of monolith volume and cell density for the reference TIF under clean DPF conditions. Plots (a) and (b) are referred to pre-turbo and post-turbo DPF placement respectively. The coordinates of the computed cases are pointed out by black circles in both plots. White colour lines on the pressure drop contour are identifying filtration area iso-lines.

The pressure drop trend shows that this is mainly dependent on the monolith volume with lower dependence on the cell density. The comparison between both DPF placements confirms the pressure drop reduction with pre-turbo DPF configuration. It is due to the higher gas density and lower velocity for the same geometry what reduces the pressure drop [10]. It can be noted how the difference in pressure drop with respect to the post-turbo DPF configuration increases as volume reduces, both in absolute and percentage terms. A volume reduction from 2.41 to 11 gives as a result that the pressure drop is multiplied approximately by 3.5 in pre-turbo placement but by 5 in the case of post-turbo placement.

An analysis at constant volume reveals that there is an optimum cell density for either DPF placement. Such an optimum cell density is located between 225 and 250 under clean DPF conditions and TIF $=5.59$ (reference value) independently of the monolith volume. Nevertheless, the cell density influence on the pressure drop is negligible inside the range from 200 to 300 . To extent the analysis of the optimum cell density under the constraint of constant TIF, the pressure drop of a canned DPF device can be estimated applying a lumped parameter model based on incompressible flow approach [32]:

$$
\begin{aligned}
\Delta p_{D P F} & =\frac{\mu Q}{2 V_{e}}\left(\alpha+w_{w}\right)^{2}\left[\frac{w_{w}}{\alpha k_{w}}+\frac{1}{2 k_{p l}} \ln \left(\frac{\alpha}{\alpha-2 w_{p l}}\right)\right. \\
& \left.+\frac{4 F_{w} L_{e}^{2}}{3}\left(\frac{1}{\left(\alpha-2 w_{p l}\right)^{4}}+\frac{1}{\alpha^{4}}\right)\right] \\
& +\frac{2 \rho Q^{2}}{V_{e}^{2} \alpha^{2}}\left(\alpha+w_{w}\right)^{4}\left(\varsigma_{\text {mon }}+\varsigma_{i e}+\varsigma_{o c}\right)\left(\frac{L_{e}}{\alpha}\right)^{2}
\end{aligned}
$$

Combining eq. 14 and eq. 8, the DPF pressure drop can be expressed as a function of TIF. Firstly, the term depending on the particulate layer thickness is expressed as a function of this parameter:

$$
w_{p l}=\frac{\alpha-\sqrt{\alpha^{2}-\frac{m_{p l}}{N_{i n} L_{e} \rho_{p l}}}}{2}
$$




$$
\begin{aligned}
\alpha-2 w_{p l} & =\sqrt{\alpha^{2}-\frac{m_{p l}}{N_{i n} L_{e} \rho_{p l}}}=\sqrt{\alpha^{2}-\frac{2 m_{p l}}{A_{f r} \sigma L_{e} \rho_{p l}}} \\
& =\alpha \sqrt{1-\frac{2 m_{p l} T I F^{2}}{A_{f r}(T I F-1)^{2} L_{e} \rho_{p l}}}=\alpha \Upsilon
\end{aligned}
$$

Considering the variable $\Upsilon$ independent of $\alpha$ the pressure drop can be finally written as:

$$
\begin{aligned}
\Delta p_{D P F} & =\frac{\mu Q}{2 V_{e}} \frac{T I F^{2}}{(T I F-1)^{3}} \frac{\alpha^{2}}{k_{w}}+\frac{\mu Q}{2 V_{e}}\left(\frac{T I F}{T I F-1}\right)^{2} \alpha^{2} \frac{1}{2 k_{p l}} \ln \left(\frac{1}{\Upsilon}\right) \\
& +\frac{\mu Q}{2 V_{e}}\left(\frac{T I F}{T I F-1}\right)^{2} \frac{4 F_{w} L_{e}^{2}}{3} \frac{1}{\alpha^{2}}\left(1+\frac{1}{\Upsilon^{4}}\right) \\
& +\frac{2 \rho Q^{2}}{V_{e}^{2} \alpha^{2}}\left(\frac{T I F}{T I F-1}\right)^{4} \alpha^{4}\left(\varsigma_{\text {mon }}+\varsigma_{i e}+\varsigma_{o c}\right)\left(\frac{L_{e}}{\alpha}\right)^{2}
\end{aligned}
$$

Imposing constant TIF and deriving eq. 17 with respect to $\alpha$, it is possible to obtain the optimum value of the honeycomb cell size

$$
\alpha_{\text {opt }}=\sqrt[4]{\frac{\frac{8 F_{w} L_{e}^{2}}{3}\left(\frac{1}{a}+1\right)}{\frac{2}{k_{w}} \frac{1}{T I F-1}+\frac{1}{k_{p l}} \ln \left(\frac{1}{\Upsilon}\right)}},
$$

and hence the optimum porous wall thickness and cell density:

$$
\begin{aligned}
& w_{w_{o p t}}=(T I F-1) \alpha_{o p t} \\
& \sigma_{o p t}=\frac{1}{\left(\alpha_{o p t}+w_{w_{o p t}}\right)^{2}}
\end{aligned}
$$

Figure 3 shows the optimum value of the cell density as a function of TIF, porous wall permeability (plot (a)) and channel length (plot (b)) for a clean DPF. For the reference TIF, porous wall permeability and effective length, the application of the lumped parameter model provides an optimum cell density equal to 227 , i.e. similar to the results shown in Figure 2 and obtained applying the one-dimensional compressible unsteady flow DPF model. Nevertheless, the analysis of the results in Figure 3(a) reveals that the optimum cell density is very sensitive to the porous wall permeability. As the porous wall permeability increases there is a reduction in the optimum cell density. This means not only advantages in lower pressure drop but also a significant reduction in the risk of plugging issues. Concerning TIF and channel length, the increase of these two parameters provides lower values for optimum cell density but its influence is lower than that of the porous wall permeability.

The pressure drop behaviour around the optimum cell density range shown in Figure 2 is also manifested in specific fuel consumption, which is represented in Figure 4. Plot (a) refers to the pre-turbo DPF configuration and plot (b) shows the results corresponding to the post-turbo DPF configuration. Although keeping the same trend than 
the DPF pressure drop, the bsfc magnitude scarcely varies with pre-turbo DPF placement. However, it shows high sensitivity to macro-geometry variation in post-turbo DPF configuration.

The use of pre-turbo DPF configuration is bringing almost absolute independence of the DPF sizing on fuel economy what is added to the already known effect of soot loading [33]. A volume reduction from 2.41 to 11 (-58\%) produces a bsfc change of less than $0.5 \%$.

However, the bsfc suffers an important increase as the monolith volume decreases in the case of the post-turbo DPF placement. From the higher bsfc than pre-turbo DPF configuration given by the reference geometry, a volume reduction up to $1.61(-33 \%)$ involves a bsfc increase of $0.8 \%$. This raises up to $2.1 \%$ when the volume gets $11(-58 \%)$. Given that these results are obtained in the most favourable conditions, i.e. clean DPF, the trend in bsfc precludes any possibility for volume reduction in post-turbo location and confirms the empirical rule imposing a DPF volume higher than the engine displacement [12].

The reason justifying the low sensitivity of the pre-turbo aftertreatment configuration to the DPF pressure drop change, in this study due to volume, is found in the interaction with the turbine [11]. Such an interaction is setting the engine back-pressure. In a post-turbo aftertreatment configuration, the engine back-pressure is given by the turbine pressure ratio times the sum of the ambient pressure and the aftertreatment pressure drop. However when a pre-turbo aftertreatment configuration is used, the engine back-pressure is given by the sum of the aftertreatment pressure drop and the product of the turbine pressure ratio and the ambient pressure. Besides the lower aftertreatment pressure drop, this means that the pre-turbo aftertreatment placement prevents from the DPF pressure drop multiplication by the turbine pressure ratio. Consequently the damage on pumping work of the aftertreatment elements is highly reduced.

One of the consequences of this behaviour is also related to the control of the VGT. Figure 5(a) shows that the VGT position remains constant with pre-turbo DPF placement under clean DPF conditions. However, the VGT must close as the DPF pressure drop increases in post-turbo aftertreatment placement in order to recover the required expansion ratio. It leads to further pumping work and bsfc penalty. Figure 5(b) shows how the VGT position is completely governed by the DPF pressure drop as concluded from comparing with Figure 2(b).

\subsection{DPF soot loading conditions}

Figure 6 represents the pressure drop when the DPF is loaded with $5 \mathrm{~g}$ of soot as a function of monolith volume and cell density. Despite the increase in pressure drop due to the soot loading the trend is the same as under clean DPF conditions. The only difference is the optimum cell density increase for every volume, which is falling out of the analysed range. It is due to the reduction of the permeability as inferred from eq. 18.

The importance of the porous substrate contribution to pressure drop demands an increase in SFA (increase of cell density at constant TIF). At constant volume, it would produce the decrease of the filtration velocity because of the filtration area increase. The result would be the pressure drop reduction across the porous media compensating the friction losses increase. 
Since too high cell densities may lead to plugging issues this result emphasises the selection of high permeability substrates. It could further boost the interest for heterogeneous porous walls providing high filtration efficiency with low equivalent permeability [34] overcoming the passive regeneration issues of these substrates with pre-turbo placement. Longer monoliths keeping volume would be also positive to get lower optimum cell density. In this case, the diameter reduction has been shown not to be dramatically detrimental for pressure drop keeping constant OFA (constant TIF) or increasing it (increasing TIF) since under soot loading conditions the macro-geometrical dependence is mainly in the volume [30]. Other solutions concern asymmetrical cell designs increasing filtration area and providing higher ash loading capability [35].

The absolute pressure drop difference between post-turbo and pre-turbo DPF placement increases under soot loading conditions but the percentage difference decreases. It is due to the fact that the increase is only linearly dependent on the Darcy's law being the inertial contribution scarcely affected (only small inlet cross-section reduction due to particulate layer).

Despite the pressure drop difference increase, Figure 7 shows that the increase in bsfc penalty with post-turbo DPF placement is significantly higher. The pre-turbo DPF placement is insensitive to DPF soot loading [26] and the VGT can remain practically in the same position as shown in Figure 8(a). Only clear fuel damage is observed in bsfc results at very low volumes and cell densities. According to the results represented in Figure 7(a), a reduction of $42 \%$ in volume of the reference DPF (1.4 l) would provide only an increase of $1.2 \%$ in bsfc. This volume reduction in pre-turbo location provides lower bsfc than the reference geometry in post-turbo location with the same soot loading. If the comparison is performed against the reference DPF in post-turbo placement and clean, the bsfe is the same despite the volume reduction and the soot loading condition in pre-turbo location.

In comparison with the pre-turbo DPF placement, the increase of the engine back-pressure in post-turbo DPF placement as the DPF gets loaded forces the VGT closing with respect to clean conditions. Such an effect is more evident as the volume decreases. Figure 8(b) clearly evidences this trend for the analysed operating point. The consequence is a high penalty in fuel economy. In this case the volume reduction up to $1.41(-42 \%)$ gives as a result a bsfc increase of $3.6 \%$ with respect to the reference DPF geometry.

\section{Approach to volume reduction analysis}

The trend shown in bsfc response suggests different approaches for DPF volume reduction as a function of its placement. While being very restrictive in post-turbo placement because of the fast increase in fuel consumption, the pre-turbo placement is more prone to discussion because of the low sensitivity of fuel consumption to pressure drop increase and hence to volume reduction. Additionally, lower soot loading levels are expected because of the higher temperature across the DPF [11].

According to the sample of computed DPF macro-and meso-geometries, the range for the analysis of the DPF and engine performance is very broad. Therefore, given the reference geometry, which is within the state of the art DPFs, 
the analysis of the potential for volume reduction can be approached considering the response of the DPF under two boundaries: constant specific filtration area and constant filtration area. A comprehensive analysis of the monolith volume reduction can be performed considering these constraints.

\subsection{Constant specific filtration area}

Within the monolith volume and cell density swept imposing constant TIF, the comparison at constant specific filtration area between two DPF geometries provides:

$$
S F A_{1}=S F A_{2} \rightarrow \frac{2 \alpha_{1}}{\left(\alpha_{1}+w_{w 1}\right)^{2}}=\frac{2 \alpha_{2}}{\left(\alpha_{2}+w_{w 2}\right)^{2}}
$$

Since TIF is constant, rearranging eq. 21 is obtained that

$$
\frac{2\left(T_{I F}-1\right)}{w_{w 1} T I F_{1}^{2}}=\frac{2\left(T I F_{2}-1\right)}{w_{w 2} T_{I} F_{2}^{2}} \rightarrow w_{w 1}=w_{w 2},
$$

so that the analysis at constant specific filtration area means that the honeycomb cell size and the porous wall thickness remain constant:

$$
w_{w 1}=w_{w 2} \stackrel{\frac{\alpha}{w_{w}}=T I F-1}{\longrightarrow} \alpha_{1}=\alpha_{2}
$$

Consequently, the cell unit geometric parameters ( $\sigma$, OFA, LOF, HTP (without Nu influence), MIF and STP) are also kept constant under these analysis conditions. Therefore, the DPF performance is only affected by the macrogeometry change in volume and filtration area.

Constant specific filtration area means moving at constant cell density as volume reduces in the contour plots shown in Section 3. Figure 9 shows the effect of volume reduction on DPF pressure drop as a function of volume, TIF, DPF location and soot loading in the case of constant SFA, which has been chosen to be the same as that of the reference DPF for every TIF. Despite that the selected cell density is pretty similar to the optimum value in clean conditions, the soot loading increase leads to an increasing pressure drop as volume reduces because of the fact that the filtration area is also decreased. It means the increase of the filtration velocity and the particulate layer thickness, which is shown in Figure 12(b). Consequently the Darcy's law contribution to pressure drop increases.

As discussed in Section 3, for every geometry the lower DPF pressure drop in pre-turbo placement is explained by the lower velocity across the DPF due to the higher gas density with respect to the post-turbo DPF location. This result is obtained even with the negative effect of the higher gas pressure on the permeability of the porous medium. It is caused by the slip flow correction, which is smaller as the pressure increases, like happens when changing the DPF placement from post- to pre-turbo. The slip flow effect is computed through the Stokes-Cunninham factor (SCF) [24], which multiplies the specific permeability to set the permeability of the porous medium at every operating condition. Figure 10 shows the porous wall permeability in pre-turbo (plot (a)) and post-turbo (plot (b)) placement as a function of volume, TIF and soot loading. In this case, the post-turbo permeability is only slightly higher than in pre-turbo 
placement because of the great difference between the mean free path of the gas molecules and the mean pore diameter. It provides very low Knudsen number and then SCF values very close to 1.

However, the analysis of the particulate layer permeability, which is shown in Figure 11(a), reveals an important reduction of its value with respect to post-turbo DPF placement when the DPF is placed upstream of the turbine. The SCF in the particulate layer is higher than inside the porous wall. It is due to the fact that the mean pore diameter in this porous medium, which is related to the mode diameter of the soot aggregates [36], is lower than the gas mean free path and consequently the SCF gets over 1, as shown in Figure 11(b). Consequently the particulate layer permeability becomes very dependent on the SCF. The higher gas density in pre-turbo location leads to a reduction of the molecules mean free path. It makes the Knudsen number to decrease and in turns reduces the SCF and the particulate layer permeability with respect of the post-turbo DPF configuration. Nevertheless, its contribution to pressure drop is not able to offset the pre-turbo pressure drop improvement due to other mechanisms.

Both of the DPF placements suffer the same decreasing trend in SCF and permeability in the porous media as a function of the volume. This phenomenon is an additional contribution to damage the DPF pressure drop as volume reduces.

Concerning the influence of TIF on pressure drop, it is limited in comparison to the soot loading effect. Nevertheless its increase can offset part of the volume reduction damage. Higher TIF means higher $\alpha$ to $w_{w}$ ratio. In order to keep the same cell density, the porous wall thickness must decrease and the cell size increase. Therefore an increase of SFA and filtration area is also obtained when TIF increases for the same volume and cell density. TIF increase is also involving higher OFA and STP but lower MIF and LOF.

Figure 12(a) shows the trend of $w_{w}$ with TIF. It is independent of the monolith volume because the SFA is kept for each TIF (eq. 23). Similarly, Figure 12(b) shows that the particulate layer would be thicker with TIF and volume reduction because of the lower filtration area at constant SFA. Therefore, TIF increase provides lower filtration velocity and smaller porous media thickness leading to lower pressure drop.

The increment in pressure drop as volume decreases is reflected in the bsfc increase, as shown in Figure 13. However, the incidence is clearly different between pre-turbo and post-turbo placement. Figure 13(a) shows that the monolith volume can be reduced up to $1.41(-42.5 \%)$ in pre-turbo placement. Under clean conditions, the bsfc would be kept almost unaffected and under soot loading conditions would be similar to that obtained with post-turbo placement but with clean DPF, whose fuel consumption is shown in Figure 13(b).

The low sensitivity of pre-turbo DPF placement to pressure drop increase underlines its potential for volume reduction and cost savings in aftertreatment even keeping the meso-structure. This result would be also useful regarding ash loading. Evidently, the DPF volume reduction affects negatively the ash loading capability. Nevertheless, the engine sensitivity to DPF loading in pre-turbo location is very low. It can be also understood as the capability to increase the quantity of the maximum ash mass able to be accumulated per unit of volume without negative effects on pressure drop and fuel penalty. Therefore, a margin for important DPF volume reduction can be still attainable preserving engine and DPF performance. 
However, post-turbo DPF placement is not allowing volume reduction keeping state of the art meso-structure. The increase of pressure drop due to the filtration area reduction, which is fed back by the increasing VGT closing and pressure ratio, leads to unacceptable fuel penalty even with low soot loading. Moreover, in this configuration the volume reduction results in loss of ash loading capability and higher pressure drop due to ash.

\subsection{Constant filtration area}

Results in Section 3 have shown how low permeability substrates (i.e. low porous wall permeability or increasing soot \& ash loading) find in high cell density a way to increase the filtration area and hence to reduce the damage on pressure drop and fuel consumption of monolith volume reduction.

Figure 14 shows the brake specific fuel consumption as a function of volume, TIF, placement and soot loading when the filtration area is kept constant. Its value has been chosen equal to that of the reference DPF for every TIF. Since the maximum cell density in the study has been fixed to $500 \mathrm{cpsi}$, the minimum monolith volume that can be reached is $1.541(-36.6 \%)$. The bsfc with pre-turbo DPF placement, which is represented in Figure 14(a), becomes nearly constant. In the case of the post-turbo DPF configuration, which is shown Figure 14(b), an increasing penalty is found as volume reduces although it is lower than in the case of constant specific filtration area.

This strategy concerning filtration area has as disadvantage issues related to channel plugging, mainly in post-turbo DPF placement. Hence the extended use of low cell density meso-structures in DPFs. Nevertheless, pre-turbo DPF placement can manage better cell density increase due to the higher temperature providing better passive regeneration performance and lower engine sensitivity to pressure drop increase.

Figure 15 shows the pressure drop as a function of volume, TIF, placement and soot loading when the filtration area is kept constant. Both pre-turbo and post-turbo DPF architectures are clearly benefitted in DPF pressure drop when the filtration area is kept despite of the volume reduction (comparison with Figure 9). Although the pressure drop is lower in pre-turbo DPF placement, the volume reduction is only additionally damaging it below 1.81 independently of the DPF placement and soot loading.

Although in this analysis the filtration area is the main parameter controlling the pressure drop change, these results come from a balance of different phenomena. Comparing against constant specific filtration area, to ensure a target filtration area as volume reduces leads to the following behaviour:

- Lower porous media pressure drop. According to the Darcy's law, it is produced by a reduction of filtration velocity and the porous media thickness. Figure 16(a) shows that the porous wall thickness decreases as volume does. In the case of the particulate layer thickness, which is shown in Figure 16(b), it keeps constant according to the filtration area value.

Concerning the porous wall permeability, when the porous wall is loaded it decreases with the DPF volume in the case of constant filtration area, as shown in Figure 17. However, this parameter remains almost constant when the specific filtration area is not modified (Figure 10). The reason lies in the balance between the fraction 
of porous wall with soot penetration and the fraction that is still kept clean. Assuming that the porous wall porosity and the mean pore diameter are not modified and that the soot properties are the same, the porous wall permeability is only dependent on the fraction of porous wall thickness affected by soot penetration [36]. Considering as hypothesis that the soot penetration thickness does not change with the DPF geometry, the fraction of loaded porous wall thickness with soot penetration increases in the case of constant filtration area. It is due to the fact that the porous wall thickness is reduced as volume does. As a consequence, the porous wall permeability decreases for this design condition.

Despite the trend in porous wall permeability, the particulate layer permeability is scarcely modified as volume reduces with constant filtration area, as Figure 18(a) shows, in contrast with constant specific filtration area case (Figure 11(a)). It brings very important benefits to pressure drop reduction. The reason explaining this response lies in the lower sensitivity of the Stokes-Cunningham factor to volume reduction, which is represented in Figure 18(b). This result is the consequence of all contributions lowering the pressure drop. Hence lower change in gas density and in turn almost constant SCF favouring lower pressure drop (snowball effect).

- Similar inertial pressure drop. Like constant specific filtration area case, the OFA is also constant with constant filtration area as volume reduces. Within the analysis boundaries (monolith volume and cell density swept at constant TIF), the comparison at constant filtration area between two DPF geometries involves that the specific filtration area increases linearly as volume decreases:

$$
A_{f}=c s t \Rightarrow S F A_{1} V_{1}=S F A_{2} V_{2}
$$

Expressing the specific filtration area as a function of TIF, it is obtained that

$$
\frac{2 V_{1}\left(T I F_{1}-1\right)}{w_{w 1} T I F_{1}^{2}}=\frac{2 V_{2}\left(T I F_{2}-1\right)}{w_{w 2} T I F_{2}^{2}}
$$

and being TIF constant, then

$$
\frac{V_{1}}{w_{w 1}}=\frac{V_{2}}{w_{w 2}}
$$

Consequently, the analysis under constant filtration area fulfils the following conditions:

$$
w_{w 2}=\frac{V_{2}}{V_{1}} w_{w 1} \stackrel{\frac{\alpha}{w_{w}}=T I F-1}{\longrightarrow} \alpha_{2}=\frac{V_{2}}{V_{1}} \alpha_{1}
$$

Applying these results to the definition of the OFA, it is found that this parameter remains constant: 


$$
\begin{aligned}
O F A_{2} & =\frac{\alpha_{2}^{2}}{2\left(\alpha_{2}+w_{w 2}\right)^{2}}= \\
& =\frac{\left(\frac{V_{2}}{V_{1}} \alpha_{1}\right)^{2}}{2\left(\frac{V_{2}}{V_{1}} \alpha_{1}+\frac{V_{2}}{V_{1}} w_{w 1}\right)^{2}}=O F A_{1}
\end{aligned}
$$

Under soot loading conditions, the case of constant filtration area provides higher inlet cross-section than the constant specific filtration area case for the same monolith diameter because of the lower particulate layer thickness. Therefore, a slight reduction of inertial pressure drop is expected at the monolith inlet.

- Pressure drop increase due to friction phenomena. The specific filtration area increases as volume reduces according to eq. 24. This determines a square increase of the friction factor with volume reduction for the constant filtration area case [19].

Considering the trend of the different mechanisms causing the pressure drop, the porous media contribution is controlling the overall response. The reduction in pressure drop given by the filtration area control strategy boosts its interest in sizing DPFs for pre-turbo use while preventing excessive cell density leading to channel plugging issues. From the results given in eq. 27 , the cell density varies squarely with volume ratio:

$$
\begin{aligned}
\sigma_{2} & =\frac{1}{\left(\alpha_{2}+w_{w 2}\right)^{2}}=\frac{1}{\left(\frac{V_{2}}{V_{1}} \alpha_{1}+\frac{V_{2}}{V_{1}} w_{w 1}\right)^{2}}= \\
& =\frac{V_{1}^{2}}{V_{2}^{2}\left(\alpha_{1}+w_{w 1}\right)^{2}}=\frac{V_{1}^{2}}{V_{2}^{2}} \sigma_{1}
\end{aligned}
$$

Furthermore, it can be demonstrated that the mechanical parameters MIF and STP are also kept constant:

$$
\begin{aligned}
M I F_{2} & =\frac{w_{w 2}^{2}}{\left(\alpha_{2}+w_{w 2}\right) \alpha_{2}}= \\
& =\frac{\left(\frac{V_{2}}{V_{1}} w_{w 1}\right)^{2}}{\left(\frac{V_{2}}{V_{1}} \alpha_{1}+\frac{V_{2}}{V_{1}} w_{w 1}\right) \frac{V_{2}}{V_{1}} \alpha_{1}}=M I F_{1} \\
S T P_{2} & =T I F_{2}\left(1-2 O F A_{2}\right)= \\
& =T I F_{1}\left(1-2 O F A_{1}\right)=S T P_{1}
\end{aligned}
$$

On the negative side, heat transfer parameters such as HPT and LOF suffer a square and linear increase respectively as volume reduces: 


$$
\begin{aligned}
H T P_{2} & =\frac{1}{2} N u \frac{S F A_{2}^{2}}{O F A_{2}}= \\
& =\frac{1}{2} N u \frac{V_{1}^{2}}{V_{2}^{2}} \frac{S F A_{1}^{2}}{O F A_{1}}=\frac{V_{1}^{2}}{V_{2}^{2}} H T P_{1} \\
L O F_{2} & =\frac{1}{4}\left(\frac{S F A_{2}}{O F A_{2}}-2 S F A_{2}\right)= \\
& =\frac{1}{4} \frac{V_{1}}{V_{2}}\left(\frac{S F A_{1}}{O F A_{1}}-2 S F A_{1}\right)= \\
& =\frac{V_{1}}{V_{2}} L O F_{1}
\end{aligned}
$$

On one hand it means an increase of the heat losses that should be avoided by a proper packaging and insulation. However, the main problem comes from the effect of the higher heat transfer during transient operation. Although it is very positive for the substrate it also means the reduction of energy available at the turbine inlet with pre-turbo aftertreatment placement during transient accelerations. The trends in different parameters emphasise the need of a right balance for filtration area selection as volume reduces in order to find the best solution for the trade-off between pressure drop and thermal response.

\section{Summary and conclusions}

This study has presented the results and the analysis of the DPF sizing influence on engine fuel consumption for post-turbo and pre-turbo DPF applications. The scope of the discussion is focused on the pressure drop effect and is based on a computational approach. The calculations have comprised volume and cellular geometry variations keeping constant the substrate micro-structure. For every volume the cell density is modified imposing a cell size and porous wall thickness dependence given by constant TIF. This approach has allowed covering the influence of additional cell unit geometric parameters related to fluid-dynamic, thermal and mechanical performance.

The post-turbo DPF placement has shown a worse behaviour than the pre-turbo DPF location concerning engine fuel consumption penalty. This penalty is increasing as the monolith volume decreases being specially damaging under soot loading conditions. Results confirm theoretically that the general rule of DPF volume being at least equal to the engine displacement works right.

The analysis has revealed that as volume reduces the pressure drop performance can be recovered increasing the cell density, i.e. the filtration area. However, the lower capability for ash accumulation can become a critical constraint. Since in post-turbo DPF placement the average soot loading is expected to be high, problems regarding inlet channel plugging may also arise as the cell density is increased. Results on optimum cell density have shown that the value resulting in minimum pressure drop reduces as permeability and monolith length increase. Other approaches to reduce the optimum cell density could be devoted to increase the filtration area, for example through TIF increase. 
It also improves the strain tolerance but may damage MIF. These solutions are also available for pre-turbo DPF placement.

The results obtained with pre-turbo DPF placement have confirmed the lower pressure drop caused by the DPF in this location and how the differences positively growth as the DPF gets loaded. The fuel consumption is scarcely sensitive to volume and soot loading changes because of the pressure drop location with respect to the turbine. Consequently the VGT control calibration becomes less sensitive to these variables.

From a fluid-dynamic point of view, it has been shown that the DPF volume may be reduced more than $40 \%$ in pre-turbo placement. This reduction would not have effect on fuel economy under clean DPF conditions. Under soot loading operation the fuel consumption would be even lower than that in post-turbo placement with clean DPF. As in post-turbo DPF placement, if the cell geometry is modified to keep constant the filtration area the benefits in pressure drop reduction lead to almost constant fuel consumption independently of the monolith volume. This solution has as limit channel plugging issues due to high cell density. Nevertheless, soot loading in pre-turbo DPF configuration is expected to be low because of the high temperature. Therefore, a balance solution between constant specific filtration area and increasing its value as volume reduces should exist. It should provide safe DPF operation and lower pressure drop with minimum fuel consumption penalty. It is also important to consider that the increase of filtration area can be obtained keeping the mechanical performance of the monolith but increasing heat transfer. This last item must be considered in pre-turbo aftertreatment applications because of the effect on the turbocharger lag under cold operating conditions.

Pre-turbo DPF configuration insensitivity to soot loading is also applicable to ash loading. The DPF volume reduction is also directly reducing the volume for ash accumulation. However, the lack of DPF loading influence on engine performance may result in the increase of critical ash mass able to be accumulated per unit of volume. The advantages in pressure drop also highlight the interest by asymmetrical cell designs because of the additional ash loading capability benefits. Consequently, volume reduction and a suitable design of the cellular geometry may provide improved fluid-dynamic response with good thermal, mechanical and ash loading performance. Therefore, a margin for important DPF volume reduction can be still attainable preserving engine and DPF performance.

\section{Acknowledgements}

This work has been partially supported by the Vicerrectorado de Investigación de la Universitat Politènica de València through grant number SP20120340-UPPTE/2012/96 and by the Conselleria de Educació, Cultura i Esport of the Generalitat Valenciana through grant number GV/2013/043. Additionally, the Ph.D. student E. Angiolini has been funded by a grant from Conselleria de Educació, Cultura i Esport of the Generalitat Valenciana with reference GRISOLIA/2013/036. These supports are gratefully acknowledged by the authors. 


\section{References}

[1] Maiboom A, Tauzia X. Experimental study of an automotive diesel engine efficiency when running under stoichiometric conditions, Applied Energy 105 (2013) 116-124.

[2] Sullivan J, Baker R, Boyer B, Hammerle R, Kenney T, Muniz L, Wallington T. $\mathrm{CO}_{2}$ emission benefit of diesel (versus gasoline) powered vehicles, Environmental Science and Technology 38(12) (2004) 3217-3223.

[3] Galindo J, Fajardo P, Navarro R, García-Cuevas LM. Characterization of a radial turbocharger turbine in pulsating flow by means of CFD and its application to engine modeling, Applied Energy 103 (2013) 116-127.

[4] Torregrosa AJ, Broatch A, García A, Mónico LF. Sensitivity of combustion noise and NOx and soot emissions to pilot injection in PCCI diesel engines, Applied Energy 104 (2) (2013) 149-157.

[5] Lednik L, Vajda B, Zunic Z, Skerget L, Kegl B. The influence of biodiesel fuel on injection characteristics, diesel engine performance, and emission formation, Applied Energy 111 (2013) 558-570.

[6] Cornolti L, Onorati A, Cerri T, Montenegro G, Piscaglia F. 1D simulation of a turbocharged diesel engine with comparison of short and long EGR route solutions, Applied Energy 111 (2013) 1-15.

[7] Johnson TV. Review of diesel emissions and control, International Journal of Engine Research 10 (2009) 275-285.

[8] Brüstle C, Downey M, Subramaniam MN, Birckett A, Tomazic D. Aftertreatment in a pre-turbo position: size and fuel consumption advantage for Tier 4 large-bore diesel engines, in: Aachen Colloquium Automobile and Engine Technology 2011, 2011.

[9] Bermúdez V, Luján JM, Piqueras P, Campos D. Pollutants emission and particle behavior in a pre-turbo aftertreatment light-duty diesel engine, Energy, In press, DOI:10.1016/j.energy.2014.02.004, 2014.

[10] Bermúdez V, Serrano JR, Piqueras P, García-Afonso O. Analysis of heavy-duty turbocharged diesel engine response under cold transient operation with a pre-turbo aftertreatment exhaust manifold configuration, International Journal of Engine Research 14 (4) (2013) 341-353.

[11] Luján JM, Bermúdez V, Piqueras P, García-Afonso O. Experimental assessment of pre-turbo aftertreatment configurations in a single stage turbocharged diesel engine. Part 1: Steady-state operation, Energy, under review, 2014.

[12] Posada F, Bandivadekar A, German J. Estimated cost of emission control technologies for light-duty vehicles. Part 2 - Diesel, in: SAE Technical Paper 2013-01-0539, 2013.

[13] U.S. Environmental Protection Agency (EPA) and U.S. National Highway Traffic Safety Administration (NHTSA). Final rulemaking to establish standards and corporate average fuel economy standards, Joint technical support document. U.S. EPA - Office of International Policy, Fuel Economy and Consumer Programs (2010).

[14] U.S. National Academy of Sciences (NAS), Assessment of fuel economy technologies for light-duty vehicles, The National Academic Press: Washington D.C. (2011).

[15] Konstandopoulos AG, Skaperdas E, Warren J, Allansson R. Optimized filter design and selection criteria for continuously regenerating diesel particulate traps, in: SAE Technical Paper 1999-01-0468, 1999.

[16] Konstandopoulos AG, Kladopoulou E. The optimum cell density for wall-flow monolithic filters: effects of filter permeability, soot cake structure and ash loading, in: SAE Technical Paper 2004-01-1133, 2004.

[17] Tsuneyoshi K, Yamamoto K. A study on the cell structure and the performances of wall-flow diesel particulate filter, Energy 48 (2012) 492-499.

[18] Lee SJ, Jeong SJ, Kim WS. Numerical design of the diesel particulate filter for optimum thermal performances during regeneration, Applied Energy 86 (2009) 1124-1135.

[19] Gulati ST. Cell design for ceramic monoliths for catalytic converter application, in: SAE Technical Paper 881685, 1988.

[20] Heck RM, Robert JF, Gulati ST. Catalytic air pollution control. Commercial Technology, John Wiley \& Sons, Inc., Hoboken, New Jersey, 2009.

[21] Depcik CD, Hausmann AJ. Review and a methodology to investigate the effects of monolithic channel geometry, Journal of Engineering for Gas Turbine and Power 135 (2013) 032301 1-16.

[22] Openwam website, CMT-Motores Térmicos (Universitat Politécnica de Valéncia). www.openwam.org (2014). 
$E_{0} \quad$ modulus of elasticity

$E_{z} \quad$ bulk modulus of elasticity

$F \quad$ minimum load carrying capacity Energy 36 (2011) 671-684. (2012) 201-213. in: SAE Technical Paper 2014-01-1498, 2014. Catalysis Today 188 (2012) 24-31.

\section{Nomenclature}

$\begin{array}{ll}A_{f} & \text { filtration area } \\ A_{f r} & \text { monolith cross-section } \\ b s f c & \text { brake specific fuel consumption } \\ D & \text { diameter } \\ \text { DOC } & \text { diesel oxidation catalyst } \\ \text { DPF } & \text { diesel particulate filter } \\ E_{0} & \text { modulus of elasticity } \\ E_{z} & \text { bulk modulus of elasticity } \\ F & \text { minimum load carrying capacity }\end{array}$

23] Galindo J, Serrano JR, Arnau FJ, Piqueras P. Description of a semi-independent time discretization methodology for a one-dimensional gas dynamics model, Journal of Engineering for Gas Turbines and Power 131 (2009) 034504.

[24] Torregrosa AJ, Serrano JR, Arnau FJ, Piqueras P. A fluid dynamic model for unsteady compressible flow in wall-flow diesel particulate filters,

25] Galindo J, Serrano JR, Piqueras P, García-Afonso O. Heat transfer modelling in honeycomb wall-flow diesel particulate filters, Energy 43

26] Bermúdez V, Serrano JR, Piqueras P, García-Afonso O. Influence of DPF soot loading on engine performance with a pre-turbo aftertreatment exhaust line, in: SAE Technical Paper 2012-01-0362, 2012.

[27] Luján JM, Serrano JR, Piqueras P, García-Afonso O. Experimental assessment of a pre-turbo aftertreatment configuration in a single stage turbocharged diesel engine. Part 2: Transient operation, Energy, under review, 2014.

[28] Payri F, Desantes JM, Piqueras P, Serrano JR. Device for treating exhaust gases from diesel turbo-supercharged reciprocating internal combustion engines (RICE), Patent WO 2013/041747 A1. Priority date 23/09/2011. European Patent Office. (2013).

[29] Gulati ST. Performance parameters for advanced ceramic catalyst supports, in: SAE Technical Paper 1999-01-0269, 1999.

[30] Serrano JR, Guardiola C, Piqueras P, Angiolini E. Analysis of the aftertreatment sizing for pre-turbo DPF and DOC exhaust line configuration,

[31] Merkel GA, Beall DM, Hickman DL, Vernacotola MJ. Effects of microstructure and cell geometry on performance of cordierite diesel particulate filters, in: SAE Technical Paper 2001-01-0193, 2001.

[32] Payri F, Broatch A, Serrano JR, Piqueras P. Experimental - theoretical methodology for determination of inertial pressure drop distribution and pore structure properties in wall-flow diesel particulate filters (DPFs), Energy 36 (2011) 6731-6744.

[33] Bermúdez V, Serrano JR, Piqueras P, García-Afonso O. Assessment by means of gas dynamic modelling of a pre-turbo diesel particulate filter configuration in a turbocharged HSDI diesel engine under full-load transient operation, Proceedings of the Institution of Mechanical Engineers, Part D: Journal of Automobile Engineering 225 (9) (2011) 1134-1155.

[34] Bollerhoff T, Markomanolakis I, Koltsakis G. Filtration and regeneration modeling for particulate filters with inhomogeneous wall structure,

[35] Bardon S, Bouteiller B, Bonnail N, Girot P, Gleize V, Oxarango L, Higelin P, Michelin J, Schuerholz S, Terres F. Asymmetrical channels to increase DPF lifetime, in: SAE Technical Paper 2004-01-950, 2004.

[36] Serrano JR, Arnau FJ, Piqueras P, García-Afonso O. Packed bed of spherical particles approach for pressure drop prediction in wall-flow DPFs (diesel particulate filters) under soot loading conditions, Energy 58 (2013) 644-654. 


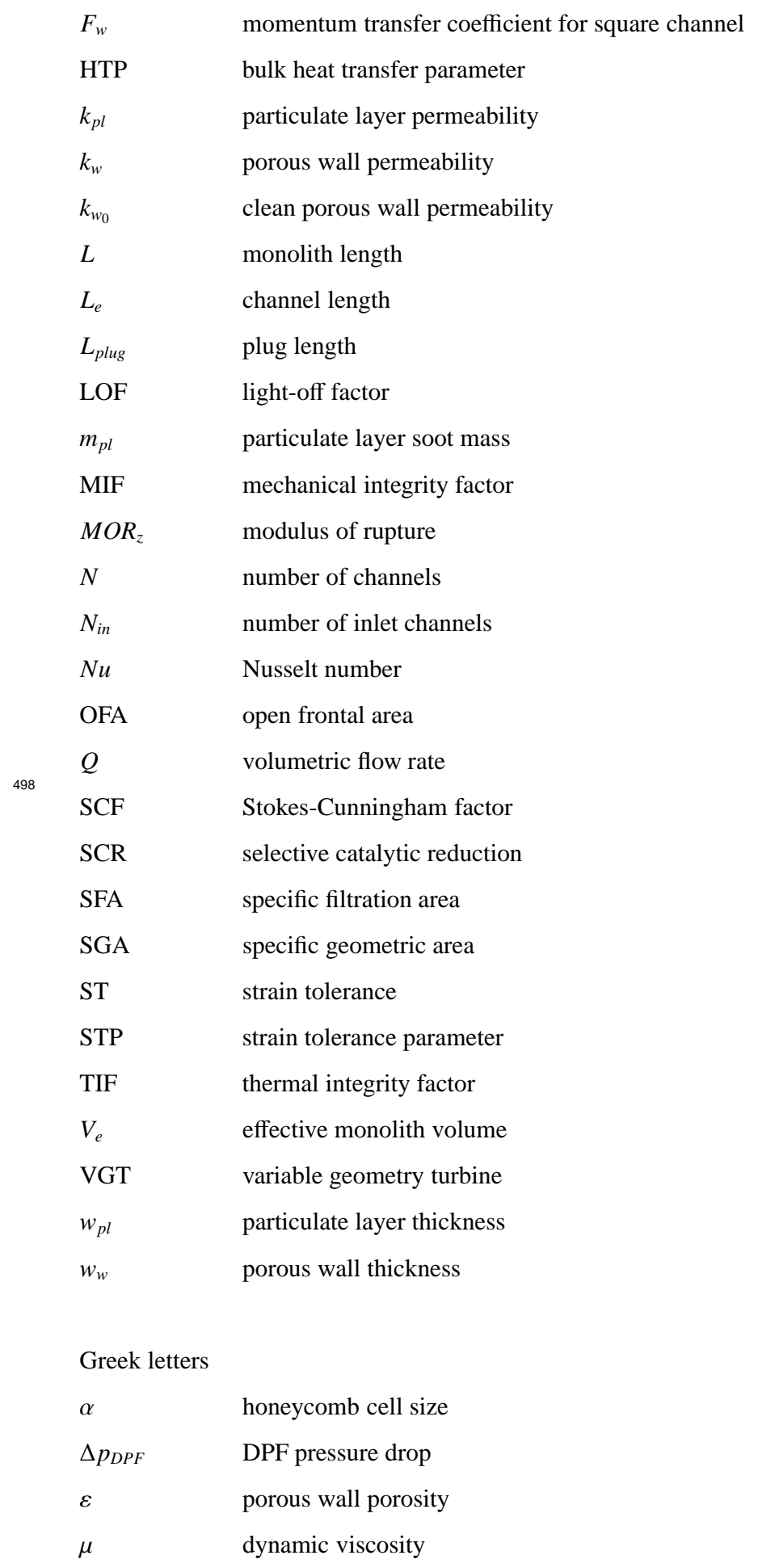




$\begin{array}{ll}\rho & \text { gas density } \\ \rho_{p l} & \text { particulate layer density } \\ \sigma & \text { cell density } \\ \sigma_{w} & \text { tensile strength of porous cell wall } \\ \varsigma & \text { pressure drop coefficient }\end{array}$

\section{Subscripts}

$\begin{array}{ll}\text { ie } & \text { expansion at inlet cone } \\ \text { in } & \text { inlet } \\ \text { mon } & \text { monolith } \\ \text { oc } & \text { contraction at outlet cone } \\ \text { opt } & \text { optimum value } \\ \text { pl } & \text { particulate layer } \\ w & \text { porous wall }\end{array}$




\section{List of Tables}

- Table 1.- Main engine characteristics.

- Table 2.- Reference DPF characteristics.

\section{List of Figures}

- Figure 1.- Comparison between experimental data and modelled results for post-turbo and pre-turbo aftertreatment configurations.

- Figure 2.- DPF pressure drop as a function of monolith volume and cell density for TIF=5.59 and clean DPF conditions: a) Pre-turbo b) Post-turbo.

- Figure 3.- Optimum cell density dependence on TIF, clean porous wall permeability and channel length.

- Figure 4.- Brake specific fuel consumption as a function of monolith volume and cell density for TIF=5.59 and clean DPF conditions: a) Pre-turbo b) Post-turbo.

- Figure 5.- VGT position as a function of monolith volume and cell density for TIF=5.59 and clean DPF conditions: a) Pre-turbo b) Post-turbo.

- Figure 6.- DPF pressure drop as a function of monolith volume and cell density for $\mathrm{TIF}=5.59$ and $5 \mathrm{~g}$ of soot loading: a) Pre-turbo b) Post-turbo.

- Figure 7.- Brake specific fuel consumption as a function of monolith volume and cell density for TIF=5.59 and $5 \mathrm{~g}$ of soot loading: a) Pre-turbo b) Post-turbo.

- Figure 8.- VGT position as a function of monolith volume and cell density for TIF=5.59 and $5 \mathrm{~g}$ of soot loading: a) Pre-turbo b) Post-turbo.

- Figure 9.- Effect of volume, TIF, placement and soot loading on DPF pressure drop with constant SFA.

- Figure 10.- Effect of volume, TIF, placement and soot loading on porous wall permeability with constant SFA.

- Figure 11.- Effect of volume, TIF, placement and soot loading on particulate layer permeability and SCF with constant SFA.

- Figure 12.- Effect of volume, TIF, placement and soot loading on porous media thickness with constant SFA.

- Figure 13.- Effect of volume, TIF, placement and soot loading on brake specific fuel consumption with constant SFA.

- Figure 14.- Effect of volume, TIF, placement and soot loading on brake specific fuel consumption with constant filtration area.

- Figure 15.- Effect of volume, TIF, placement and soot loading on DPF pressure drop with constant filtration area.

- Figure 16.- Effect of volume, TIF, placement and soot loading on porous media thickness with constant filtration area.

- Figure 17.- Effect of volume, TIF, placement and soot loading on porous wall permeability with constant filtration area.

- Figure 18.- Effect of volume, TIF, placement and soot loading on particulate layer permeability with constant filtration area. 
Table 1: Main engine characteristics.

\begin{tabular}{ll}
\hline \hline Type & HSDI E4 diesel engine \\
Displacement & $1997 \mathrm{~cm}^{3}$ \\
Diameter & $85 \mathrm{~mm}$ \\
Stroke & $88 \mathrm{~mm}$ \\
Number of cylinders & 4 in line \\
Valves & 4 per cylinder \\
Compression ratio & $18: 1$ \\
Maximun power & $100 \mathrm{~kW}$ at $4000 \mathrm{rpm}$ \\
Maximun torque & $320 \mathrm{Nm}$ at $1750 \mathrm{rpm}$ \\
Turbocharger & Single-stage VGT \\
\hline \hline
\end{tabular}


Table 2: Reference DPF characteristics.

\begin{tabular}{lcc}
\multicolumn{3}{c}{ Table 2: Reference DPF characteristics. } \\
\hline \hline Diameter & {$[\mathrm{mm}]$} & 135 \\
Length & {$[\mathrm{mm}]$} & 170 \\
Plug length & {$[\mathrm{mm}]$} & 5 \\
Monolith volume & {$[1]$} & 2.43 \\
Porosity & {$[-]$} & 0.46 \\
Mean pore diameter & {$[\mu m]$} & 14.4 \\
Porous wall permeability & {$\left[\mathrm{m}^{2}\right]$} & $3.85 \times 10^{-13}$ \\
Cellular geometry & & Square \\
Honeycomb cell size & {$[\mathrm{mm}]$} & 1.47 \\
Wall thickness & {$[\mathrm{mm}]$} & 0.32 \\
N ${ }^{\text {of channels }}$ & {$[-]$} & 4470 \\
Filtration area & {$\left[\mathrm{m}^{2}\right]$} & 2.17 \\
SFA & {$[1 / \mathrm{m}]$} & 917.6 \\
SGA & {$[1 / \mathrm{m}]$} & 1835.2 \\
Cell density $(\sigma)$ & {$[\mathrm{cpsi}]$} & 200 \\
OFA & {$[-]$} & 0.34 \\
TIF & {$[-]$} & 5.59 \\
LOF & {$[1 / \mathrm{m}]$} & 215.9 \\
MIF & {$[-]$} & 0.0389 \\
STP & {$[-]$} & 1.82 \\
\hline \hline
\end{tabular}


a)



c)

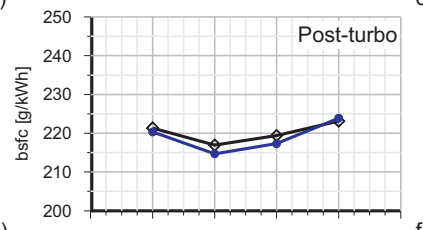

e)
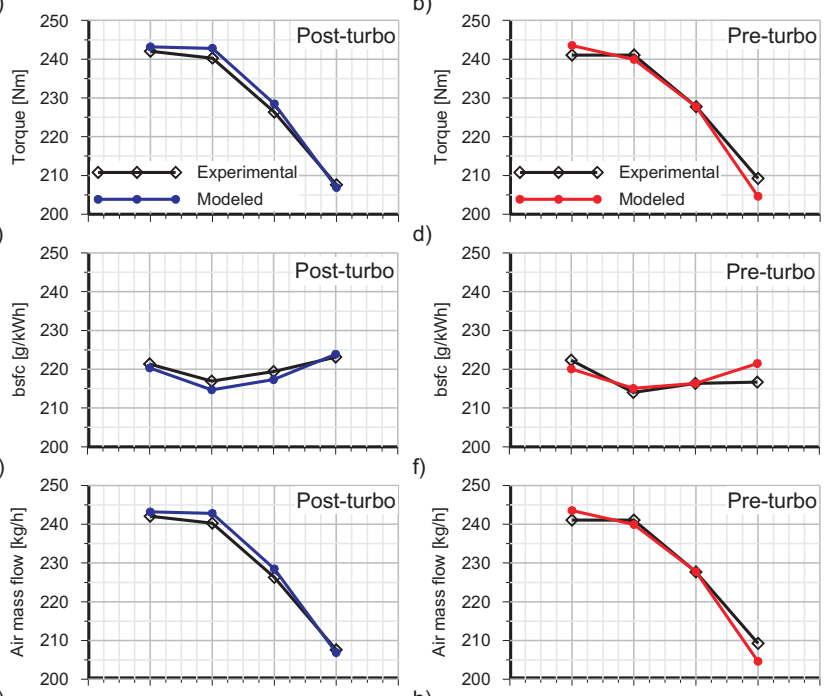

d)
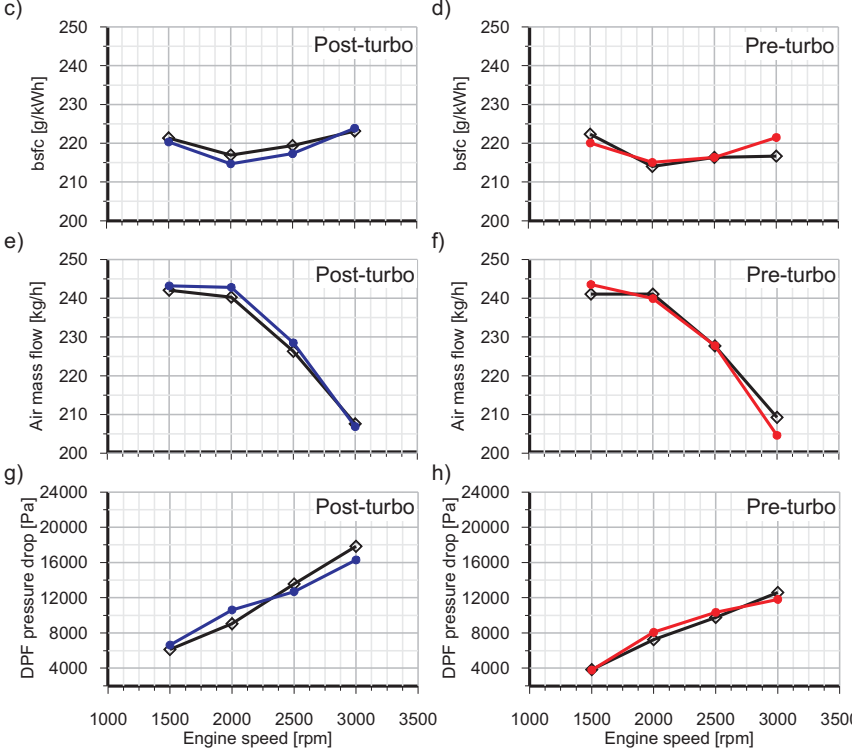

h) 200

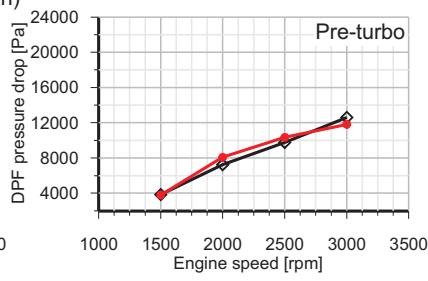

Figure 1: Comparison between experimental data and modelled results for post-turbo and pre-turbo aftertreatment configurations. 
a) Pre-turbo DPF pressure drop [Pa]



b) Post-turbo DPF pressure drop [Pa]

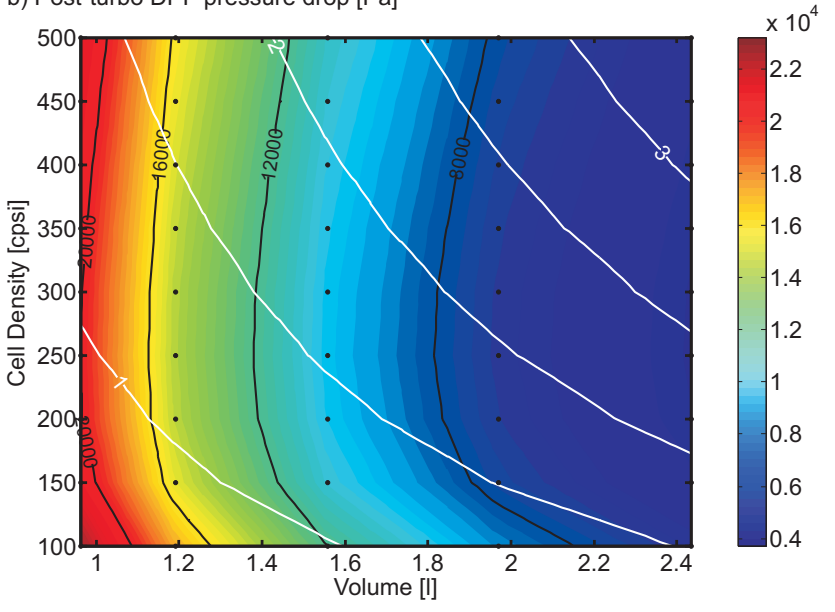

Figure 2: DPF pressure drop as a function of monolith volume and cell density for TIF=5.59 and clean DPF conditions: a) Pre-turbo b) Post-turbo. 


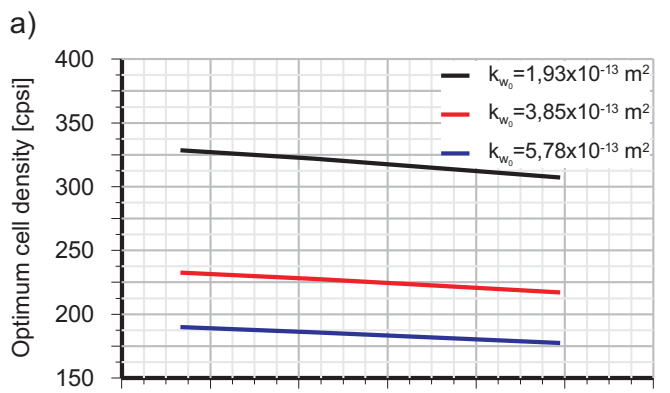

b)



Figure 3: Optimum cell density dependence on TIF, clean porous wall permeability and channel length. 


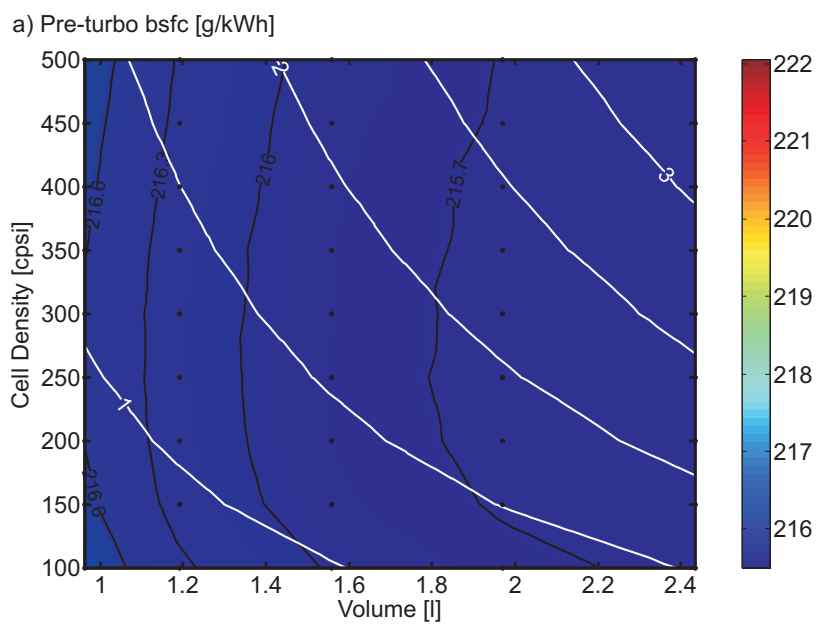

b) Post-turbo bsfc [g/kWh]

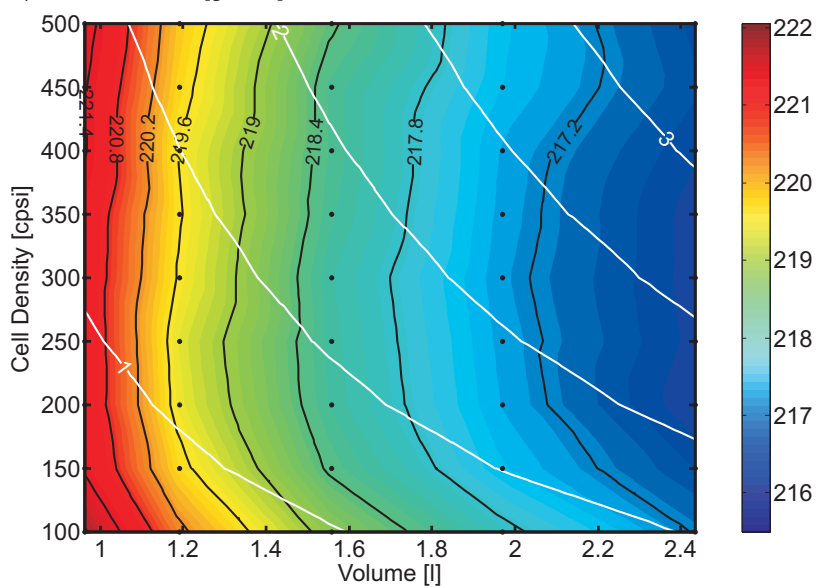

Figure 4: Brake specific fuel consumption as a function of monolith volume and cell density for TIF=5.59 and clean DPF conditions: a) Pre-turbo b) Post-turbo. 


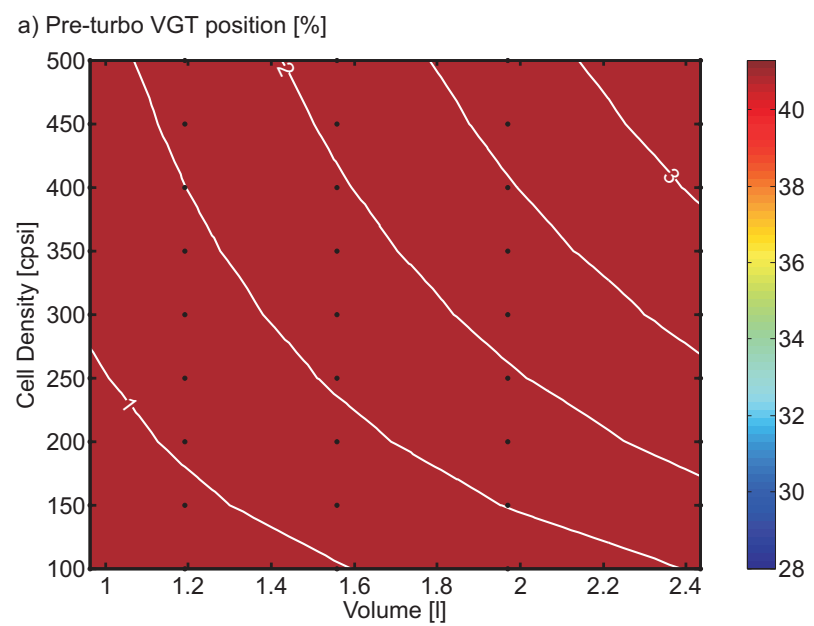

b) Post-turbo VGT position [\%]

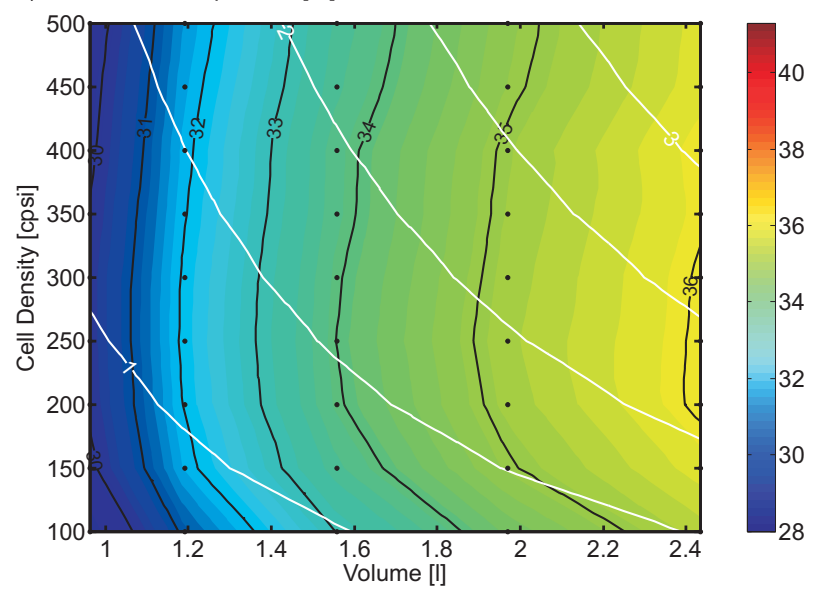

Figure 5: VGT position as a function of monolith volume and cell density for TIF=5.59 and clean DPF conditions: a) Pre-turbo b) Post-turbo. 

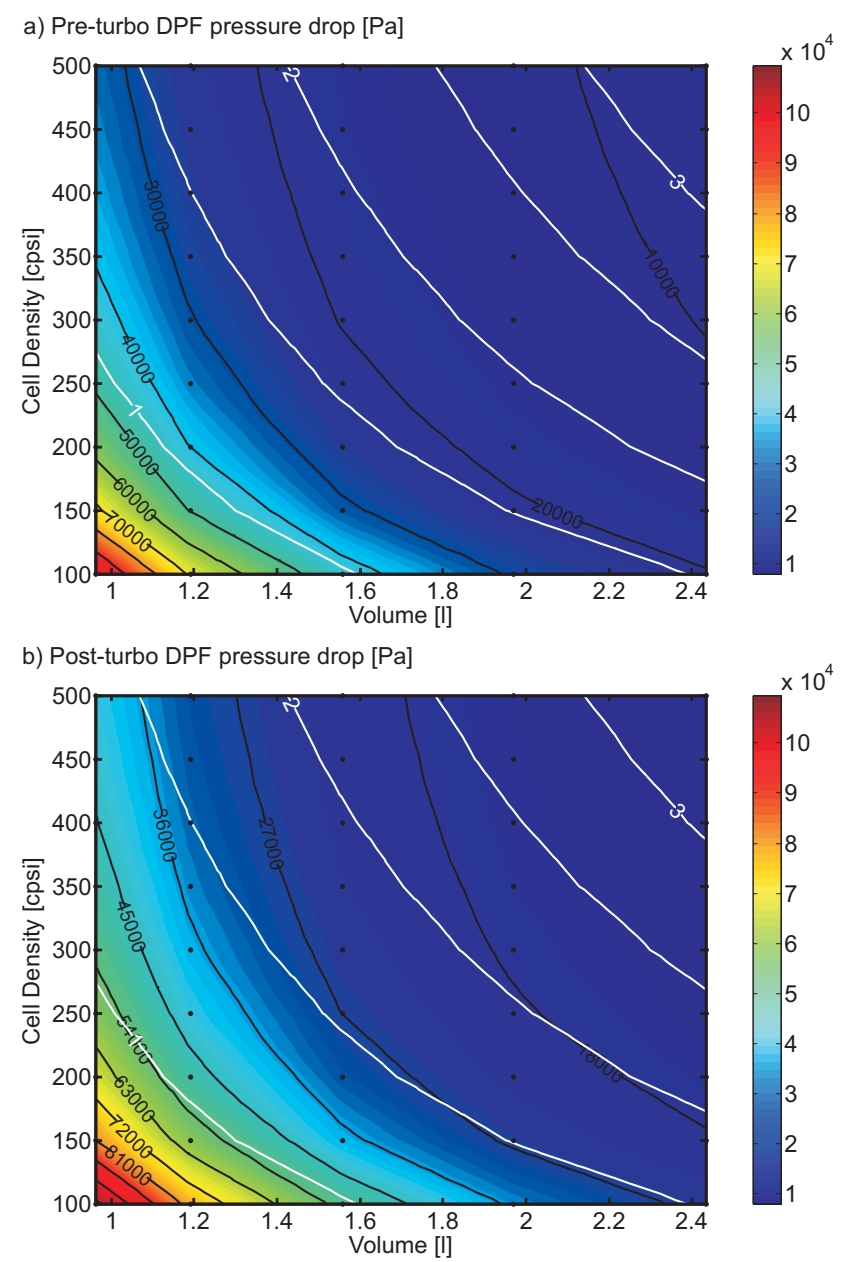

Figure 6: DPF pressure drop as a function of monolith volume and cell density for TIF=5.59 and $5 \mathrm{~g}$ of soot loading: a) Pre-turbo b) Post-turbo. 


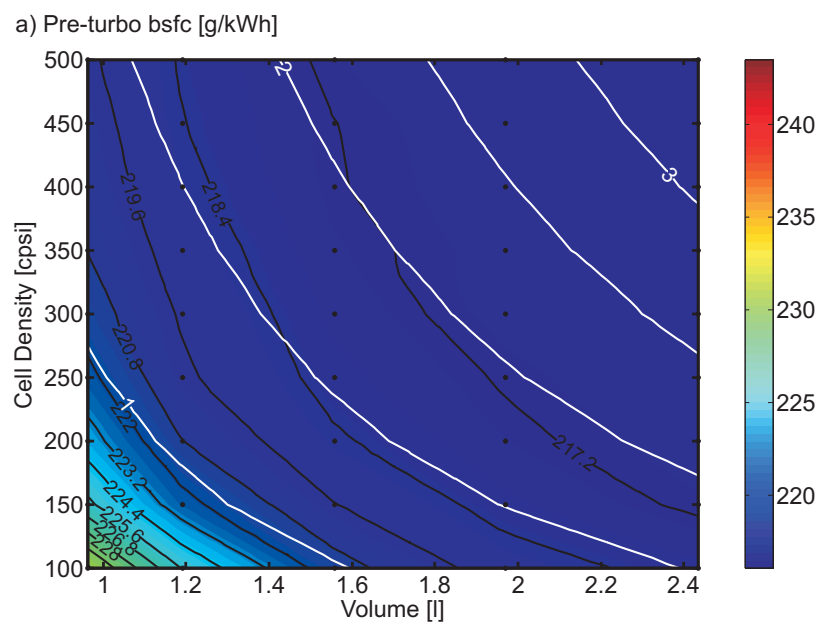

b) Post-turbo bsfc [g/kWh]



Figure 7: Brake specific fuel consumption as a function of monolith volume and cell density for TIF=5.59 and $5 \mathrm{~g}$ of soot loading: a) Pre-turbo b) Post-turbo. 


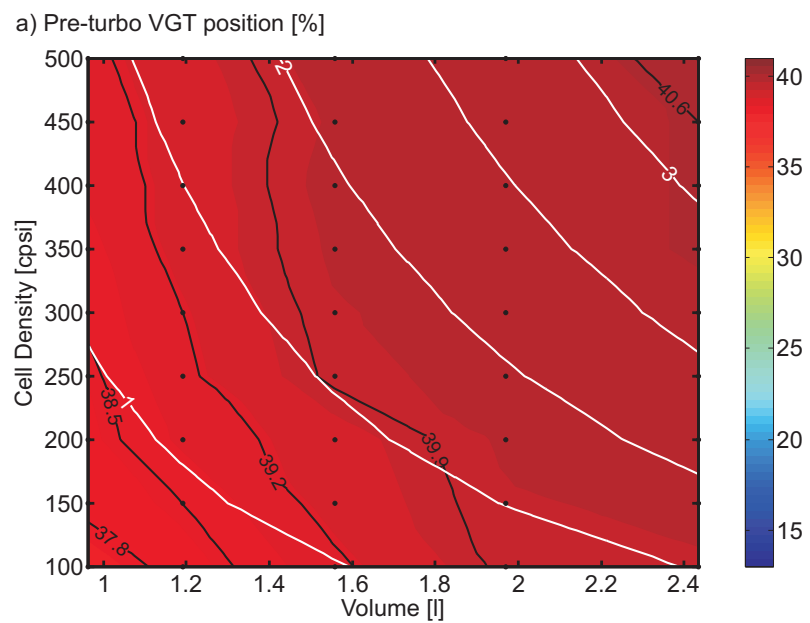

b) Post-turbo VGT position [\%]

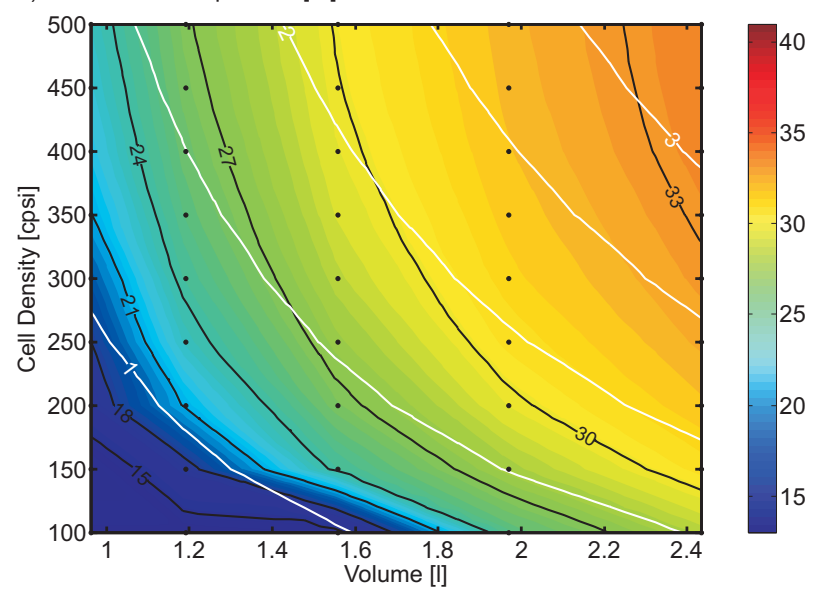

Figure 8: VGT position as a function of monolith volume and cell density for TIF=5.59 and $5 \mathrm{~g}$ of soot loading: a) Pre-turbo b) Post-turbo. 


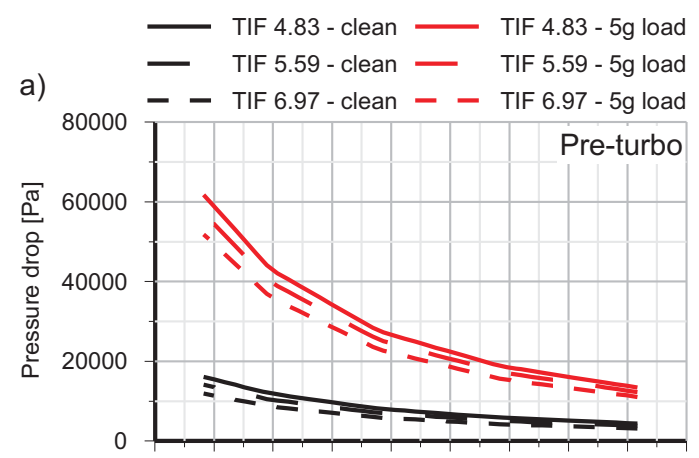

b)

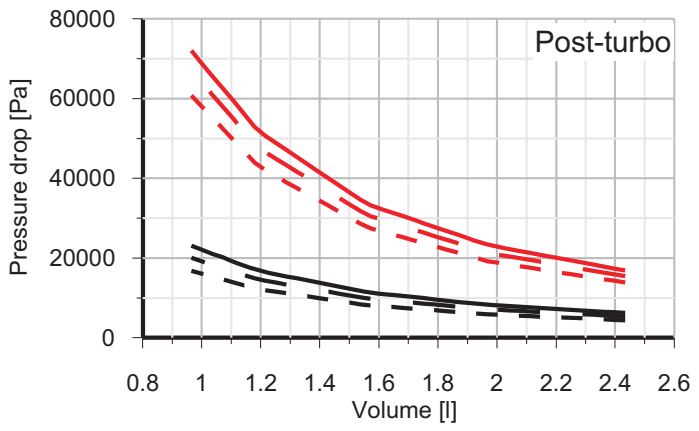

Figure 9: Effect of volume, TIF, placement and soot loading on DPF pressure drop with constant SFA. 


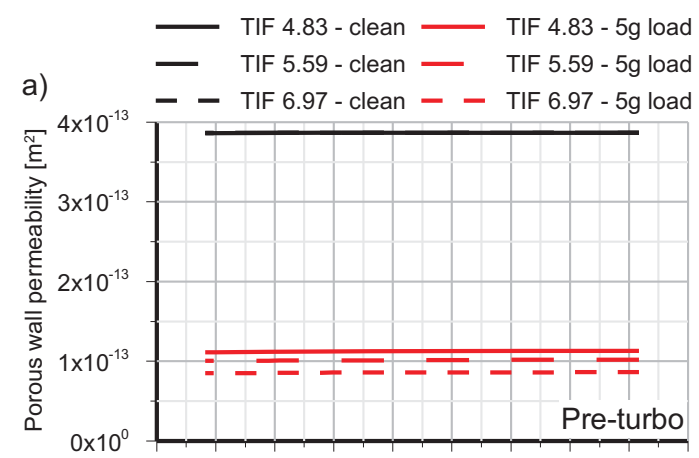

b)

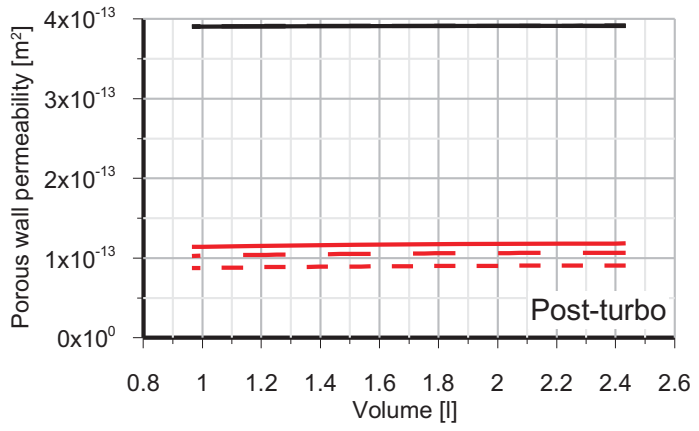

Figure 10: Effect of volume, TIF, placement and soot loading on porous wall permeability with constant SFA. 


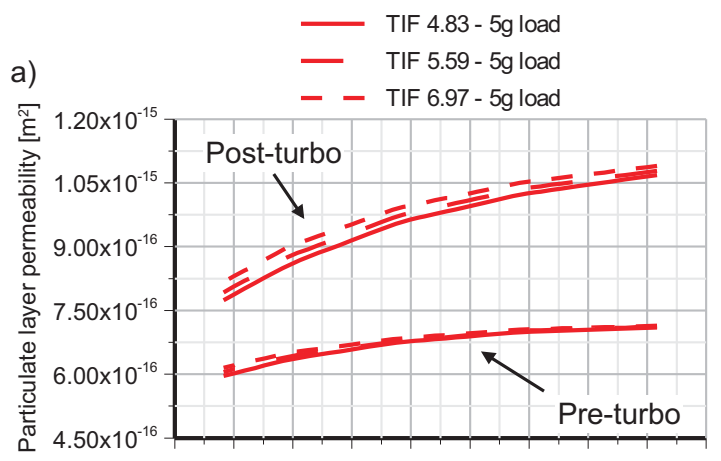

b)

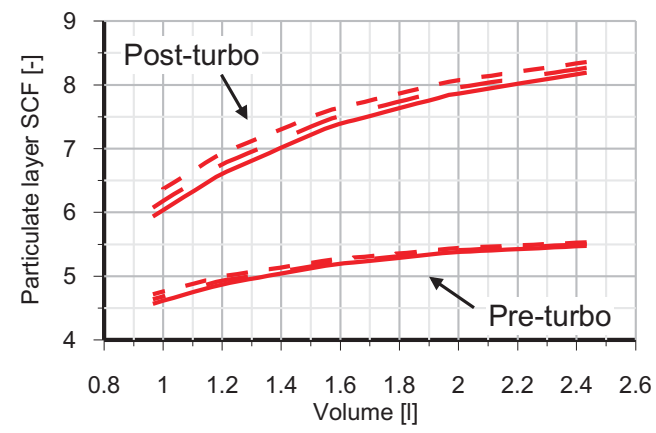

Figure 11: Effect of volume, TIF, placement and soot loading on particulate layer permeability and SCF with constant SFA.

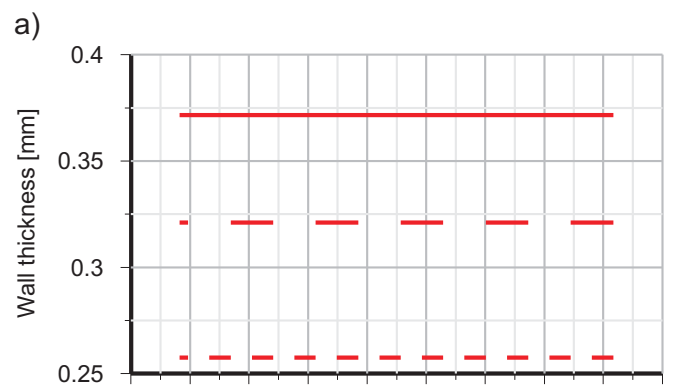

b)

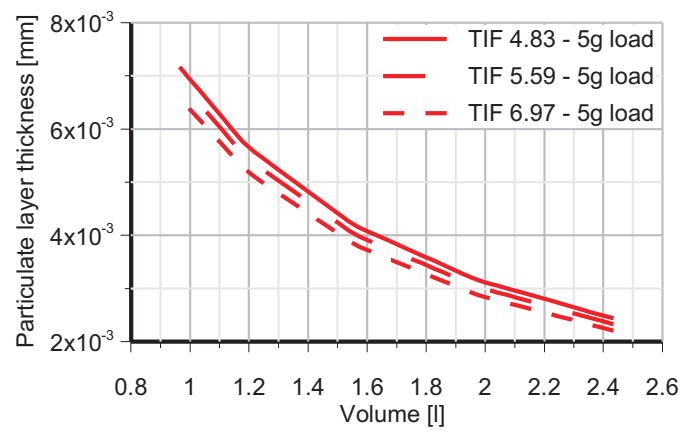

Figure 12: Effect of volume, TIF, placement and soot loading on porous media thickness with constant SFA. 


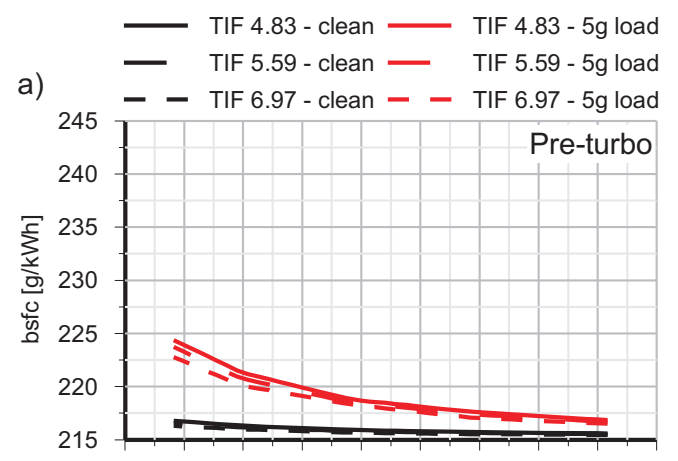

b)

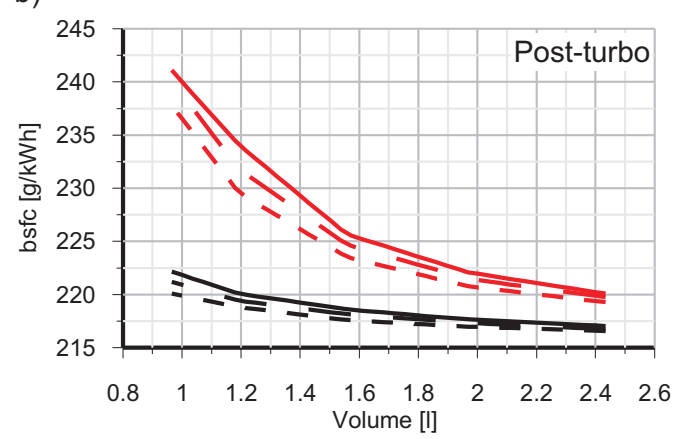

Figure 13: Effect of volume, TIF, placement and soot loading on brake specific fuel consumption with constant SFA. 


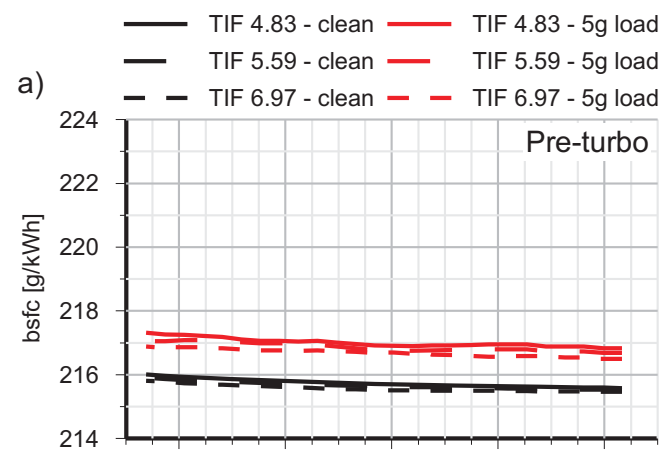

b)

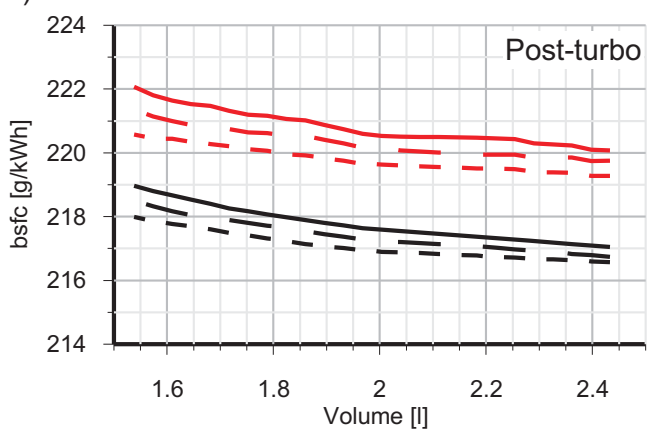

Figure 14: Effect of volume, TIF, placement and soot loading on brake specific fuel consumption with constant filtration area. 


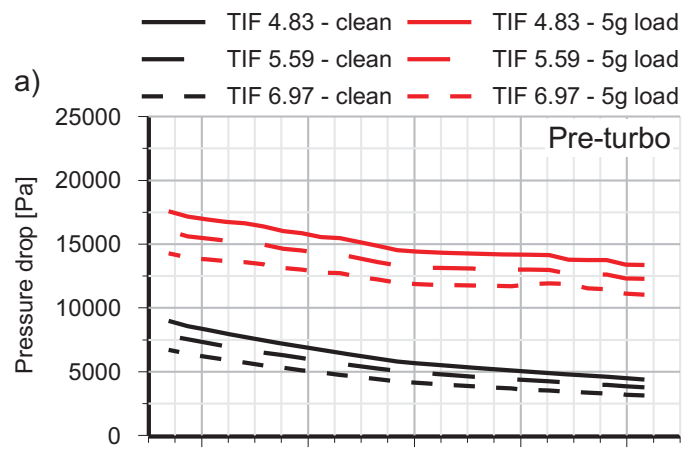

b)



Figure 15: Effect of volume, TIF, placement and soot loading on DPF pressure drop with constant filtration area.

a)

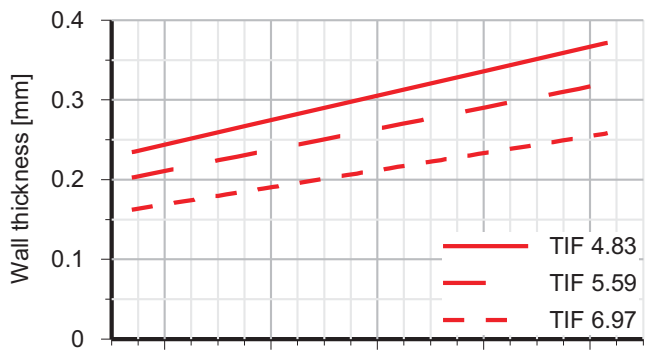

b)

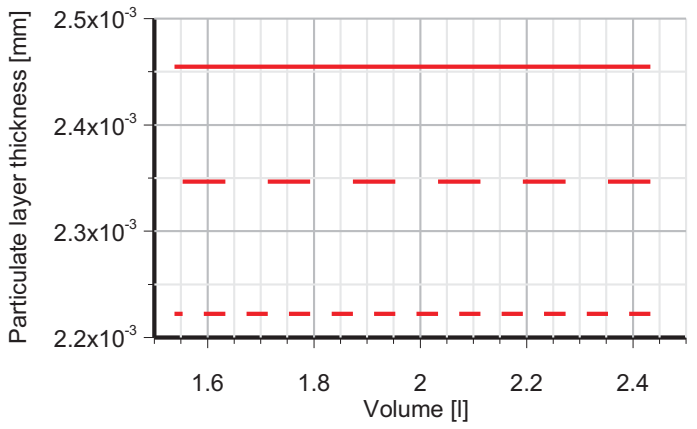

Figure 16: Effect of volume, TIF, placement and soot loading on porous media thickness with constant filtration area. 


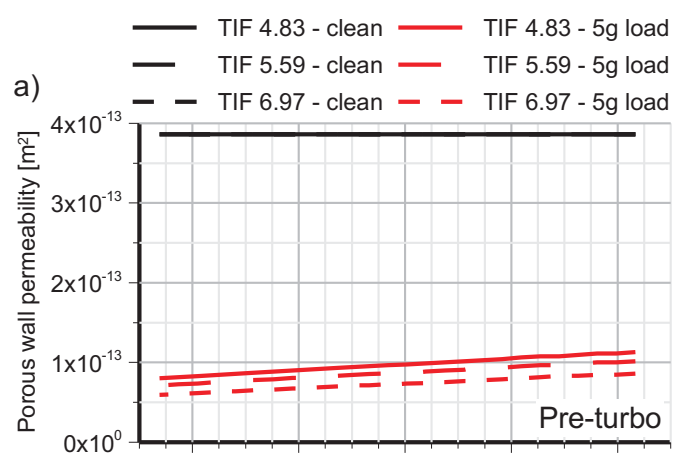

b)

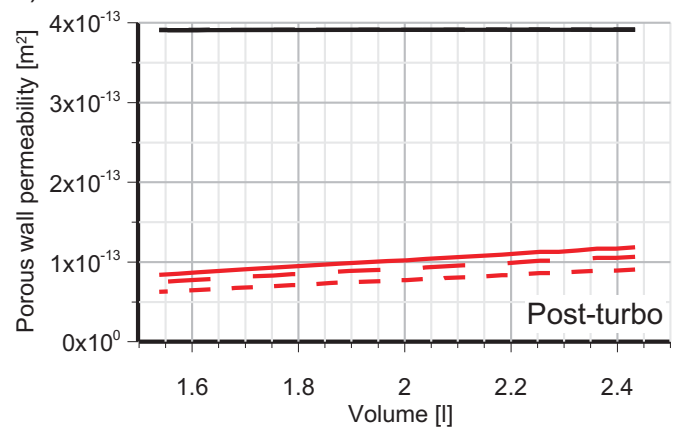

Figure 17: Effect of volume, TIF, placement and soot loading on porous wall permeability with constant filtration area.



b)

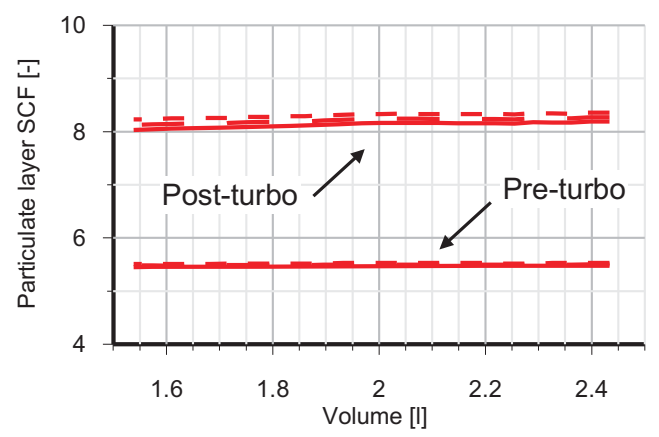

Figure 18: Effect of volume, TIF, placement and soot loading on particulate layer permeability with constant filtration area. 